\title{
Tropical Oceanic Causes of Interannual to Multidecadal Precipitation Variability in Southeast South America over the Past Century*
}

\author{
RICHARD SEAGER AND NAOMI NAIK \\ Lamont-Doherty Earth Observatory of Columbia University, Palisades, New York \\ WALTER BAETHGEN AND ANDREW ROBERTSON \\ International Research Institute for Climate and Society, Palisades, New York \\ YOCHANAN KUSHNIR AND JENNIFER NAKAMURA \\ Lamont-Doherty Earth Observatory of Columbia University, Palisades, New York \\ STEPHANIE JURBURG \\ Columbia College, Columbia University, New York, New York
}

(Manuscript received 15 December 2009, in final form 3 June 2010)

\begin{abstract}
Observations, atmosphere models forced by historical SSTs, and idealized simulations are used to determine the causes and mechanisms of interannual to multidecadal precipitation anomalies over southeast South America (SESA) since 1901. About 40\% of SESA precipitation variability over this period can be accounted for by global SST forcing. Both the tropical Pacific and Atlantic Oceans share the driving of SESA precipitation, with the latter contributing the most on multidecadal time scales and explaining a wetting trend from the early midcentury until the end of the last century. Cold tropical Atlantic SST anomalies are shown to drive wet conditions in SESA. The dynamics that link SESA precipitation to tropical Atlantic SST anomalies are explored. Cold tropical Atlantic SST anomalies force equatorward-flowing upper-tropospheric flow to the southeast of the tropical heating anomaly, and the vorticity advection by this flow is balanced by vortex stretching and ascent, which drives the increased precipitation. The 1930s Pampas Dust Bowl drought occurred, via this mechanism, in response to warm tropical Atlantic SST anomalies. The atmospheric response to cold tropical Pacific SSTs also contributed. The tropical Atlantic SST anomalies linked to SESA precipitation are the tropical components of the Atlantic multidecadal oscillation. There is little evidence that the large trends over past decades are related to anthropogenic radiative forcing, although models project that this will cause a modest wetting of the climate of SESA. As such, and if the Atlantic multidecadal oscillation has shifted toward a warm phase, it should not be assumed that the long-term wetting trend in SESA will continue. Any reversal to a drier climate more typical of earlier decades would have clear consequences for regional agriculture and water resources.
\end{abstract}

\section{Introduction}

Southeastern South America (SESA), here defined as the area east of the Andes between $20^{\circ} \mathrm{S}$ and

* Lamont-Doherty Earth Observatory Contribution Number 7383.

Corresponding author address: Richard Seager, Oceanography, Lamont-Doherty Earth Observatory of Columbia University, Palisades, NY 10964.

E-mail: seager@ldeo.columbia.edu $40^{\circ} \mathrm{S}$-including southern Brazil, Paraguay, Uruguay, and northern Argentina-has experienced a trend toward increased precipitation throughout most of the last century (Liebmann et al. 2004; Haylock et al. 2006; Barros et al. 2008). This has enabled a growth in agricultural production (Viglizzo and Frank 2006) and sustained an increase in river flow (Genta et al. 1998). In addition, precipitation over SESA has varied on interannual to decadal time scales, having serious impacts on agriculture, streamflow, water resources, and power generation (e.g., Robertson and Mechoso 1998). Indeed, there is substantial evidence that SESA underwent a multiyear 
drought, soil erosion, and dust storms during the 1930s just as North America did, the so-called Pampas Dust Bowl (Viglizzo and Frank 2006). Improved understanding of the causes of interannual to multidecadal precipitation variability has the potential to translate into improved prediction and incorporation of climate information into regional planning on interannual and much longer time scales. A particular question that needs to be answered is whether the long-term wetting trend within the last century is natural or anthropogenic and whether it will continue or reverse. The future of agriculture in SESA will depend in large part on what the answer to this question is.

Much work has been done linking SESA precipitation on interannual time scales to the El Niño-Southern Oscillation (ENSO) with El Niño conditions being shown to cause increased precipitation (Aceituno 1988; Pisciottano et al. 1994; Grimm et al. 2000; Pezzi and Cavalcanti 2001; Paegle and Mo 2002; Grimm 2003). El Niño conditions have also been shown to lead to increased flow in the rivers that drain SESA (e.g., Robertson and Mechoso 1998). The link to ENSO is strongest in austral spring, weak in summer, and stronger again in fall (Grimm et al. 2000; Cazes-Boezio et al. 2003; Barreiro 2010), a seasonal dependence that probably reflects the weaker teleconnections in the austral summer atmosphere (Cazes-Boezio et al. 2003), even as ENSO sea surface temperature (SST) anomalies peak in that season. The ENSO influence on SESA precipitation, when it works, can be understood in terms of tropical SST and heating anomalies forcing the Pacific-South America (PSA) teleconnection pattern (Mo and Higgins 1998; Kidson 1999; Grimm 2003) and also in terms of an influence on the Southern Hemisphere jet stream, transient eddy propagation, and eddy-driven vertical motion (Seager et al. 2003, 2005a). Grimm and Zilli (2009), while emphasizing the ENSO connection, also suggest that regional soil moisture-atmosphere feedbacks, triggered by ENSO in the spring, can cause summer precipitation anomalies. The atmospheric response to tropical Pacific decadal variability (PDV) works in a similar way to the response to ENSO and partly explains wetter conditions in SESA for the two decades following the 1976/77 warm shift in tropical Pacific SSTs (Huang et al. 2005). Further, it has been argued that the ENSO impact on SESA precipitation is influenced by the phase of Pacific decadal variability (Andreoli and Kayano 2005; Barreiro 2010).

ENSO does not fully explain the potentially predictable part of SESA precipitation variability. Other workers have examined the effect of variability in the South Atlantic convergence zone (SACZ) on SESA precipitation and have identified links of the SACZ and SESA precipitation to SST anomalies in the subtropical and tropical
Atlantic Ocean, although there is much debate as to the extent to which the SACZ variability forces South Atlantic SST anomalies or vice versa (Robertson and Mechoso 2000; Pezzi and Cavalcanti 2001; Barreiro et al. 2002; Doyle and Barros 2002; Paegle and Mo 2002; Haarsma et al. 2003; Trzaska et al. 2007; see also Chaves and Nobre 2004; De Almeida et al. 2007; Taschetto and Wainer 2008), and there is probably considerable internal atmospheric variability of the SACZ that is unpredictable. Robertson and Mechoso (1998) also found a link between cold tropical Atlantic SSTs and increased river flow in SESA. The dynamical mechanisms for a control on SESA precipitation of Atlantic SST anomalies are not fully understood. The southern annular mode (SAM), the leading mode of Southern Hemisphere atmospheric circulation variability (Thompson and Wallace 2000), has a seasonally varying impact on SESA precipitation (Silvestri and Vera 2003), but in part this reflects the strong link between ENSO and the SAM (L'Heureux and Thompson 2006). It also appears that the influence may not have been stable over time (Silvestri and Vera 2009). Chan et al. (2008) have also argued for an effect of Indian Ocean SST anomalies on South American precipitation.

Despite these efforts to explain SESA precipitation variability using both observations and models, to our knowledge no one to date has assessed the ability of SSTforced atmosphere general circulation models (GCMs) to reproduce the past history of SESA precipitation as has been done, for example, for the Great Plains and southwestern North America by Schubert et al. (2004a) and Seager et al. (2005b, 2009b); for the southeast United States by Seager et al. (2009a); and for Africa by Giannini et al. (2003), Held et al. (2005), and Hoerling et al. (2006). Consequently, the causes of the actual interannual and decadal variabilty of SESA precipitation remain not fully explained. Further, the large-scale atmospheric dynamical mechanisms that link Pacific and Atlantic SSTs to SESA precipitation still require explanation, especially in the case of Atlantic forcing. Last, it has not been determined if anthropogenic climate change has contributed to SESA precipitation trends over the last century.

In the current paper, we will build on prior work and will do the following:

- Examine a century-long precipitation dataset to describe and characterize the history on interannual to multidecadal time scales of SESA precipitation. The SESA precipitation history in equivalently long model simulations forced by global SSTs, and by tropical Pacific SSTs alone, will be examined.

- Analyze observed and modeled precipitation to determine the links between SSTs and SESA precipitation 
variability and the associated circulation anomalies. The links to the tropical Pacific and the Atlantic Oceans will be examined.

- Analyze large ensembles of 100-day-long atmosphere GCM simulations in which a tropical Atlantic SST anomaly is imposed on day 1 to determine cause and effect in the response of SESA precipitation to tropical Atlantic SST anomalies.

It will be concluded that, despite the precipitation impacts of annular mode and other variability not forced by SST anomalies, a surprisingly large portion of SESA precipitation variability is caused by variations in SST, with the tropical Pacific and Atlantic Oceans providing the driving. These together explain most of the interannual to multidecadal variations, including the wetting trend from the 1930s on. However, the long-term wetting trend is at best partially explained in this manner and, if it is real, remains a mystery since it is much larger than that obtained from simulations of radiatively forced SESA precipitation change.

\section{Data and models}

The precipitation data used are the $1^{\circ} \times 1^{\circ}$ gridded data from the Global Precipitation Climatology Centre (GPCC) and covers 1901-2007 (Rudolf et al. 1994; Schneider et al. 2008). The station coverage varies considerably with just 42 stations in the SESA region in January 1901, most of those being in northeast Argentina, increasing to more than 1000 in the early 1990s with good coverage. The main increase in coverage occurs in 1950; however, we chose to use all the data because of our interest in long-term variations and in the 1930s drought and because, after checking, we saw no reason to exclude the early data (see next section). To examine circulation anomalies we use the National Centers for Environmental Prediction-National Center for Atmospheric Research (NCEP-NCAR) reanalysis, which covers 1949 to the present (Kalnay et al. 1996; Kistler et al. 2001). SST data are taken from the Met Office Hadley Centre Sea Ice and Sea Surface Temperature (HadISST) dataset (Rayner et al. 2003).

The atmosphere GCM used is the NCAR Community Climate Model 3 (CCM3) (Kiehl et al. 1998) run with triangular truncation at total wavenumber 42 and 18 vertical levels. Two 16-member ensembles are analyzed. The first is forced with the time history of observed SSTs across the global oceans. The SSTs are from the Hadley dataset except between $20^{\circ} \mathrm{S}$ and $20^{\circ} \mathrm{N}$ and across the global oceans from 1856 to 1870 where the Kaplan et al. (1998) dataset is used because it begins earlier. This is the Global Ocean Global Atmosphere (GOGA) ensemble. The second ensemble uses imposed historical
SSTs in the tropical Pacific $\left(20^{\circ} \mathrm{S}-20^{\circ} \mathrm{N}\right)$ only and computes SST with a two-level entraining mixed layer ocean elsewhere. A specified " $q$ flux" is imposed in the mixed layer ocean to mimic the effects of dynamical ocean heat transport. This is the Pacific Ocean Global AtmosphereMixed Layer (POGA-ML) model. More details on the models and their setup can be found in Seager et al. (2005b). All simulations began with different January initial conditions on 1 January 1856, but here, to coincide with the GPCC precipitation data, only the 1901-2007 period is analyzed.

To examine radiatively forced climate change we used all 24 models participating in the Intergovernmental Panel on Climate Change Fourth Assessment Report (IPCC AR4), also known as the Coupled Model Intercomparison Project phase 3 (CMIP3) (Meehl et al. 2007), examining their simulations from 1900 to 1999 with historical trace gas, aerosol, solar and volcanic forcings, and, in some cases, changes in land use, linking these with the "middle of the road" Special Report on Emissions Scenarios (SRESA1B) for the 2000-07 period.

\section{Analysis of observed precipitation variability and change and links to global SSTs}

The problem to be addressed is shown in Fig. 1: the 1901-2007 history of annual mean precipitation in the SESA region (land areas east of the Andes from $64^{\circ} \mathrm{W}$ to the coast and from $20^{\circ}$ to $40^{\circ} \mathrm{S}$ is shown as a box in Fig. 2). The observed precipitation (black line) shows a centurylong wetting trend that is clear amid considerable interannual variability. There is also evidence of decadal variability, in particular a dry period between about 1930 and 1970 and a persistently wet period from about 1970 into the early years of the current decade. Consistent with descriptions of the existence of a "Pampas Dust Bowl," the 1930s stand out as one period of prolonged below normal precipitation, with the late 1940s to mid-1950s as another period.

The long-term trend to wetter conditions appears to be influenced by some very prominent dry spells in the early part of the century when few rain gauges appear in the GPCC dataset. Since the area average could be influenced by shifts in the regions of data coverage, we have also examined the century-long precipitation histories in individual grid boxes within the GPCC dataset that have continual coverage. In these, the wetting trend also appears in more cases than not (not shown). We conclude that there is no reason to a priori reject the century-long wetting trend as unreal, but it should be treated with caution. Computing a linear trend by least squares shows the positive trend to be highly statistically significant for both the 1901-2007 period and, if 


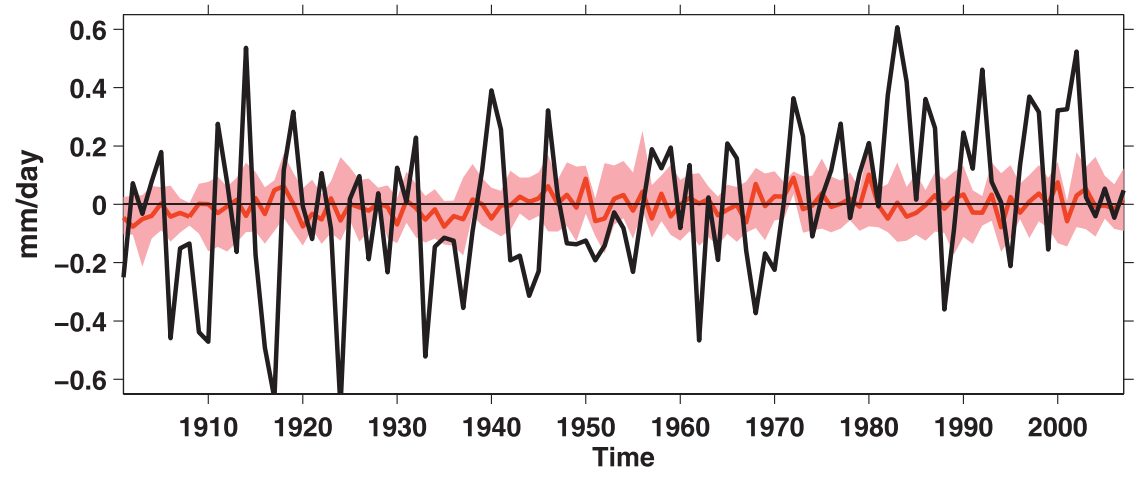

FIG. 1. The observed GPCC (black line) and the IPCC AR4 simulated and projected (SRESA1B) median (red line) and area between the 25th and 75th percentiles of the 24-model distribution (pink shading) precipitation anomalies area-averaged over SESA. Units are $\mathrm{mm}$ day $^{-1}$.

the earlier data are discarded, also for the 1930-2007 period.

Figure 1 also shows the median and 25th and 75th percentiles of the 24-model distribution of simulations of radiatively forced climate change for the 1901-2007 period. The wetting trend in these is extremely weak and much smaller than that derived from the GPCC data. Indeed, the observed trend is outside of the range of trends simulated by the 24 AR 4 models. The spatial patterns of the observed and AR4-simulated trends for all of South America are shown in Fig. 2. The trend simulated as a response to radiative forcing has drying north of the equator and wetting over most of the rest of the continent, including over SESA, except for drying over most of Chile and southern Argentina. This spatial pattern bears some relation to the observed trend with the exceptions that the latter has a region of drying around $10^{\circ}-20^{\circ} \mathrm{S}$ and much stronger wetting in the central Amazon and over SESA. SESA is also projected to get wetter in the current century (Vera et al. 2006; Boulanger et al. 2007), but even this is by less than the observed wetting trend to 2007. However, these same references point out that current generation climate models have limited skill in simulating precipitation over SESA and the SACZ, which may compromise their simulations of past and future radiatively forced change. Hence, while it is possible that the observed wetting trend is contributed to by anthropogenic climate change, it is also possible that it is dominated by multidecadal timescale natural variability with an amplitude greater than that contained within any of the AR4 models.

To examine links between SESA precipitation variability and global SSTs we next correlated Hadley SSTs onto the SESA precipitation index by season: MarchMay (MAM), June-August (JJA), September-November (SON), and December-February (DJF). Using a $t$ test and assuming years are independent of each other, a correlation coefficient in excess of 0.25 (0.19) would be significant at the $99 \%$ (95\%) confidence level. As shown in Fig. 3, all seasons show a link between wet in SESA and an El Niño-like state; however, this is strongest in SON, consistent with Grimm et al. (2000), Cazes-Boezio et al. (2003), and Barreiro (2010), and very weak in JJA. To examine this further we therefore correlated the GPCC precipitation data onto an index of tropical Pacific (TP) SST, defined as the area-average SST anomaly between $5^{\circ} \mathrm{S}$ and $5^{\circ} \mathrm{N}$, and $180^{\circ}$ and $90^{\circ} \mathrm{W}$ (longitudinally just broader than the Niño-3.4 index), again by season (Fig. 4). El Niño conditions induce dry conditions across northern South America and wet conditions focused in SESA with the strongest correlations in SON and weakest in JJA.

On the basis of these correlations and in agreement with previous studies, it is clear that the tropical Pacific Ocean exerts a strong influence on SESA precipitation, especially in the spring season. The SST maps do not clearly show any other ocean influence since a positive Indian Ocean correlation is expected as a result of warming in response to El Niño conditions. However, to examine the issue further, we produced a SESA precipitation index from which the influence of the tropical Pacific has been removed by regressing out the part dependent on the TP index, month by month. This leaves the wetting trend as dominant, and to isolate the non-ENSO variability we also detrended this time series. We refer to this residual time series as the "ENSOremoved detrended SESA" index. We then correlated this index with global SST, and the results are shown in Fig. 5.

By construction the ENSO-removed detrended SESA index does not correlate well with tropical Pacific SSTs. Instead, a weak correlation to Atlantic SSTs is seen with 
a) GPCC

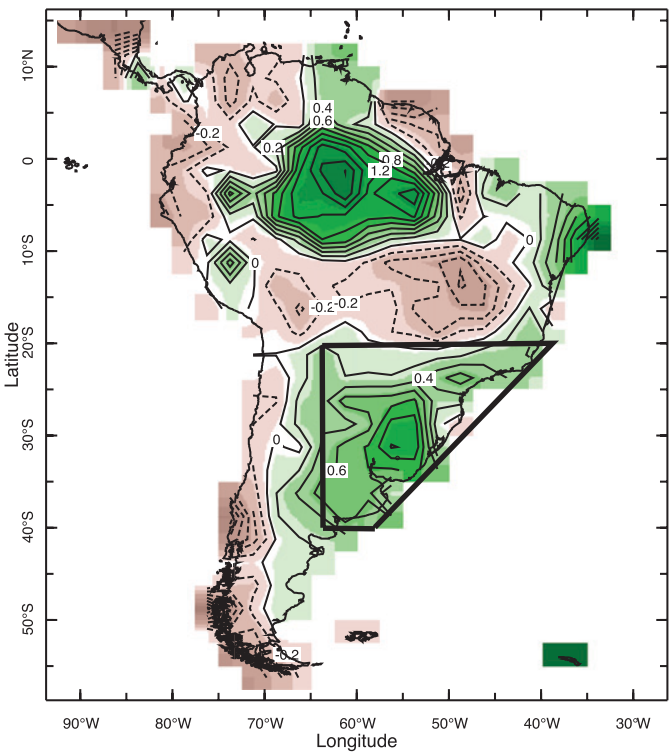

b) IPCC Mean

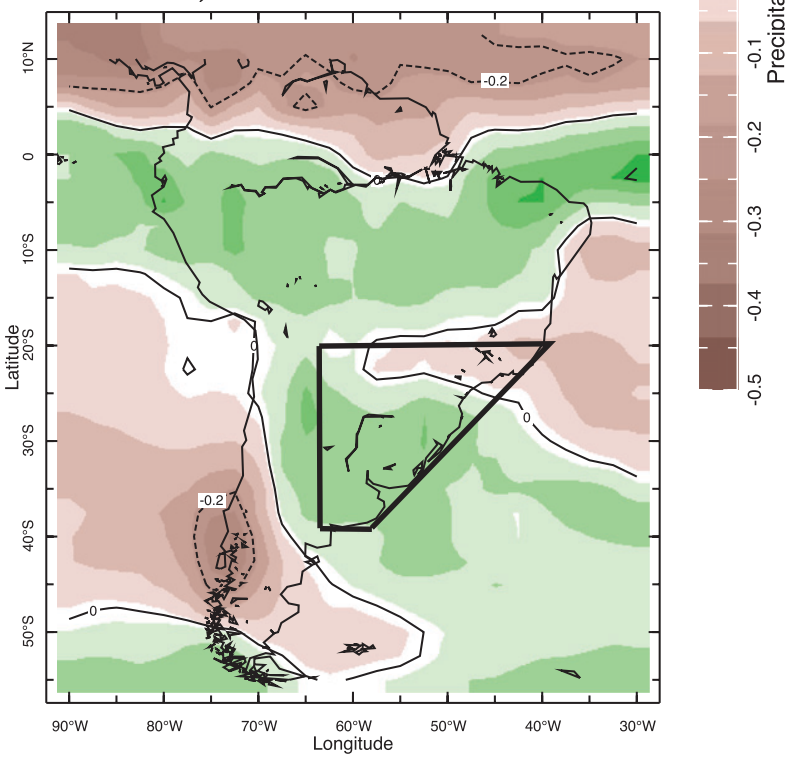

FIG. 2. The (top) GPCC observed and (bottom) SRESA1B precipitation trends for South America from 1901 to 2007. Units are $\mathrm{mm}$ day $^{-1}$ change over the entire period. The box shows the SESA area.

wetness in SESA associated with warm western subtropical South Atlantic SSTs and a cool tropical Atlantic Ocean [similar to the SST relation to increased SESA river flow found by Robertson and Mechoso (1998)]. This weak influence exists year round but is strongest in JJA. Performing the correlation with the ENSO-removed SESA index but without detrending masks the Atlantic association and picks up a correlation of wetting in SESA with widespread ocean warming. However, on the basis of the results of the IPCC AR4 simulations, which show only very weak trends in precipitation over the last century, we do not think this association is causal (i.e., it is not caused by the warming of the oceans or by the rise in greenhouse gas concentrations).

\section{Modeled associations between SESA precipitation and global SSTs}

We next repeat these correlation analyses with the GOGA-modeled SESA precipitation. The seasonal correlations between ensemble mean SESA precipitation and global SSTs also show a strong link to the tropical Pacific. Figure 6 shows the correlation of GOGA ensemble mean precipitation across South America with the GOGA TP SST index and should be compared with Fig. 4. During El Niño, the basic pattern of dry across northern South America, wet in extratropical South America, and dry in the far southern tip of South America is reproduced by the model. All of these correlations are higher than in observations simply because the model ensemble mean isolates the SST-forced precipitation signal. A significant error of the model is the very high positive correlations in SESA during JJA when the observed correlations are very weak. Otherwise, the model seems to reproduce the basics of the continent-wide teleconnection between ENSO and South American precipitation.

As will be shortly shown, the GOGA-modeled SESA precipitation does not have a century-long wetting trend. Hence, we next simply removed the ENSO influence from modeled SESA precipitation by regressing out the part linearly dependent on the TP index to create the "ENSOremoved GOGA SESA" index. This index was then correlated with global SSTs. As seen in Fig. 7, this also shows a link between wetness in SESA and the warm SSTs in the subtropical west South Atlantic Ocean and cool in the tropical Atlantic Ocean. This link is stronger than in observations, again in part because of using the model ensemble mean. In DJF, when the link to the tropical Atlantic is weaker, wetness in SESA is also correlated with warming across the Southern Ocean and a poleward shift of the mean westerlies (not shown): further examination of this link is beyond the scope of the current work.

\section{Comparison of observed and modeled SESA precipitation 1901-2007}

The above correlation results suggest that a significant amount of the SESA precipitation history should be reproduced in the SST-forced model because it can 
a) MAM

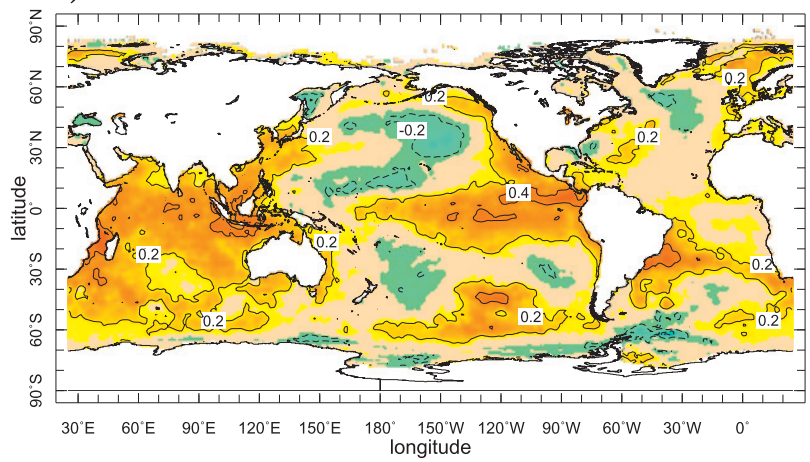

c) $\mathrm{SON}$

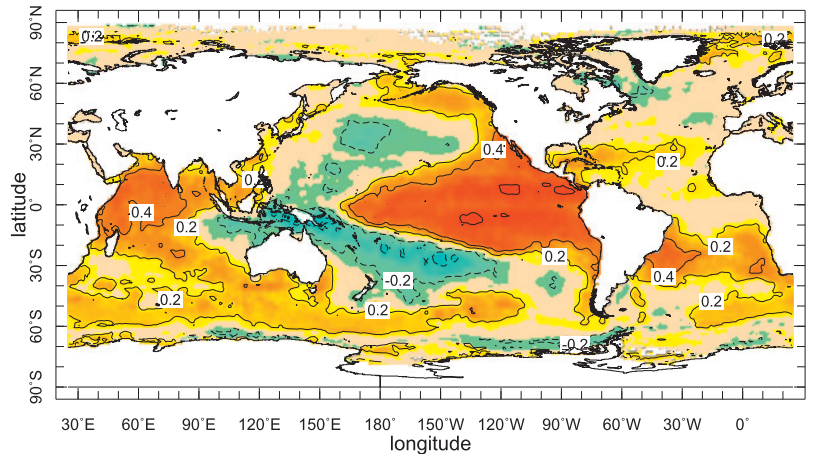

b) JJA

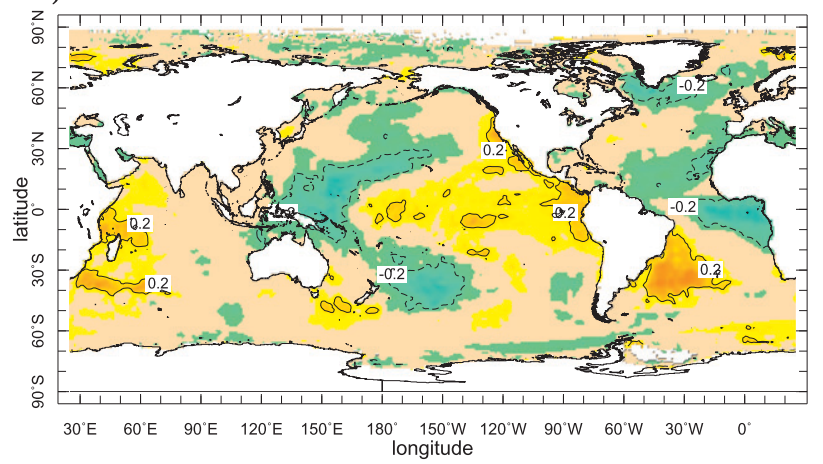

d) DJF

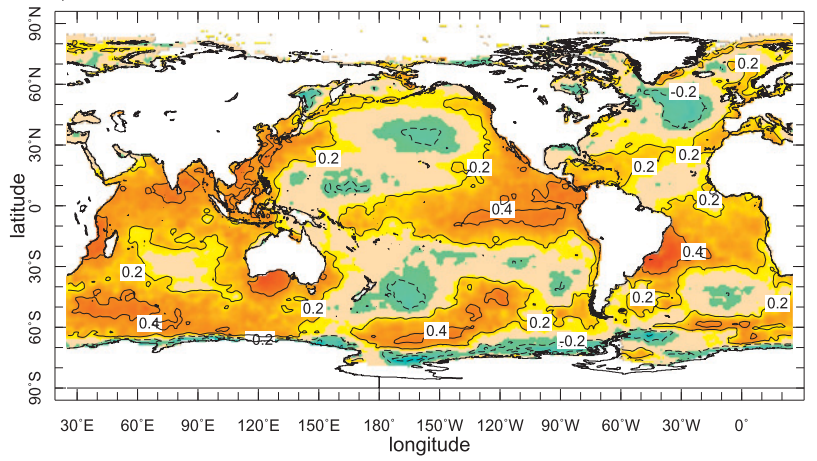

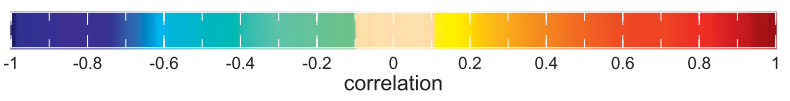

FIG. 3. Correlation between observed SESA precipitation and global SSTs by season for 1901-2007. In this and all subsequent plots of correlation coefficients (Figs. 4-7, and 10), a value of $0.25(0.19)$ would be significant at $1 \%(5 \%)$ confidence level according to a $t$ test.

correctly simulate the influences of tropical Pacific and Atlantic SSTs. The top panel of Fig. 8 shows the time history of observed annual-mean SESA precipitation together with that simulated in the ensemble mean by the GOGA model. The correlation coefficient between these time series is 0.64 , meaning that $40 \%$ of the observed variance is captured by the model as a response to SST forcing. The shading around the model line represents the plus/minus two standard deviations spread of the 16-member GOGA ensemble.

The lower panel in Fig. 8 shows the comparison of observed precipitation with that from the POGA-ML model in which only tropical Pacific SSTs are specified and a mixed layer ocean is used elsewhere. In this case only about $17 \%$ of observed SESA precipitation variance is explained by the model, suggesting that a substantial portion of the variability explained by SST variations is explained by the SST variations outside of, and possibly independent of, the tropical Pacific Ocean. It is also notable that neither the GOGA nor POGAML model simulates a century-long wetting trend because both simulate a relatively wet period in the first three decades of the twentieth century.

Despite the disagreement between the model and observations in regard to the century-long trend, the model captures important aspects of the multidecadal SESA precipitation variability, especially the drier middle of the century and shift to wetter conditions in the latter part of the century. The GOGA model ensemble mean is dry throughout the Pampas Dust Bowl drought of the 1930s, while the POGA-ML ensemble mean is not. The tropical Pacific SST forcing contributes relatively little to the multidecadal variability, as seen by comparing the POGA-ML and GOGA simulations, suggesting that it comes from SST forcing outside the tropical Pacific: the correlation maps make us suspect that it comes from the Atlantic Ocean.

To further check on the link to Atlantic SSTs, we compared the time history of ENSO-removed detrended SESA precipitation with a time series of SST averaged over the part of the tropical Atlantic that shows strong correlations $\left(20^{\circ} \mathrm{S}-20^{\circ} \mathrm{N}\right.$ across the basin), also 
a) MAM

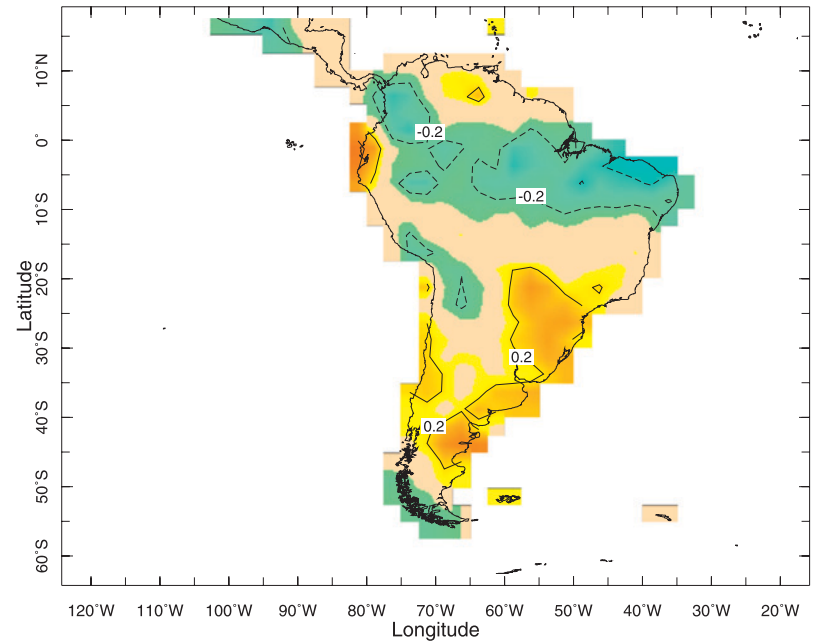

c) $\mathrm{SON}$

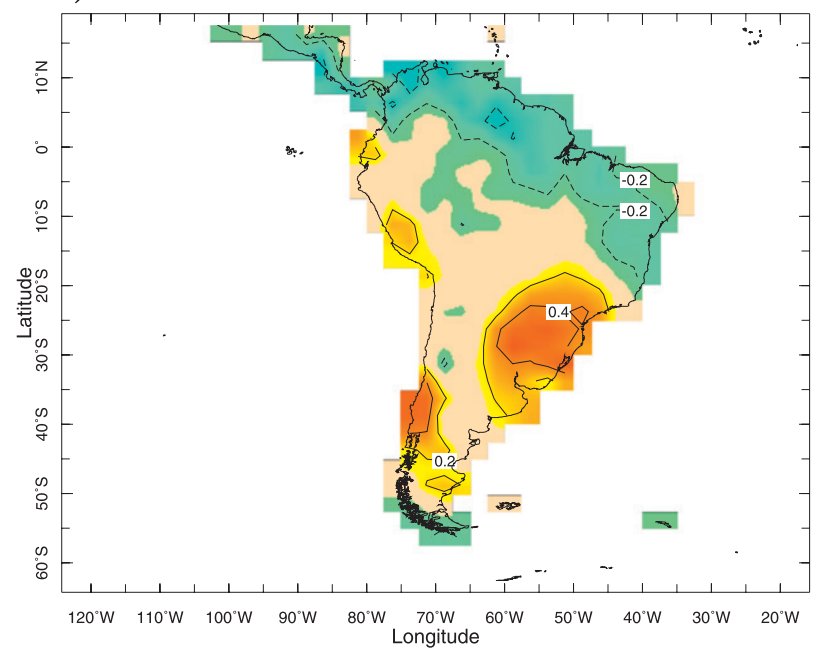

b) JJA

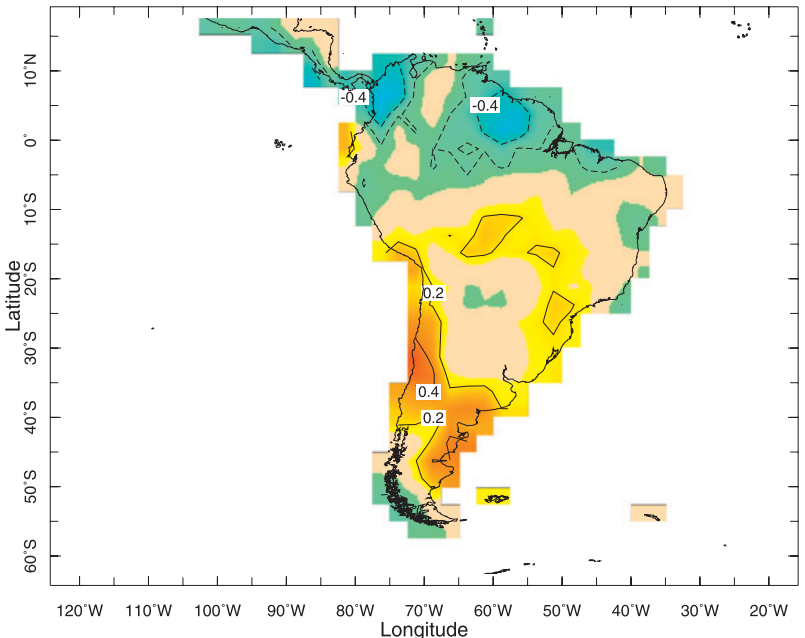

d) DJF

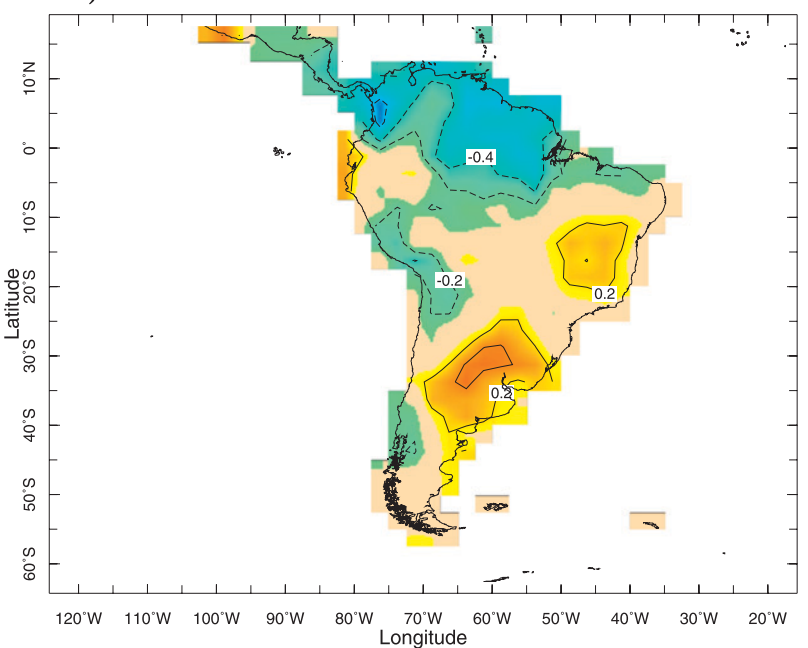

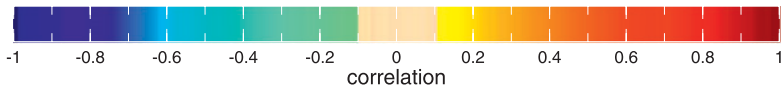

FIG. 4. Correlation between observed precipitation and the tropical Pacific (TP) SST index by season for 1901-2007.

detrended. The comparison, both for the GOGA model and for observed SESA precipitation, is shown in Fig. 9. The SST index has been multiplied by minus one for plotting. Clearly, for the model there is a very strong relation between that part of SESA precipitation variability not explained by ENSO and tropical Atlantic SST variability, with about $42 \%$ of the variance explained. For the observations the same relation remains but the variance explained is only about $7 \%$. Regardless, what is remarkable in both cases is that the increase in SESA precipitation from the 1930s to the end of the century is associated with a relative cooling of tropical Atlantic SST. A relatively warm tropical Atlantic in the earlier part of the century was also associated with a relatively dry SESA, such that there is a clear multidecadal variation in both fields.

\section{Mechanisms of tropical Atlantic SST influence on SESA precipitation}

The tropical Pacific influence on precipitation over South America has been studied before (e.g., Karoly 1989; Mo and Higgins 1998; Mo and Paegle 2001; CazesBoezio et al. 2003; Grimm 2003). Essentially, and analagous to the situation in the Northern Hemisphere, tropical Pacific heating anomalies responding to SST anomalies 
a) MAM

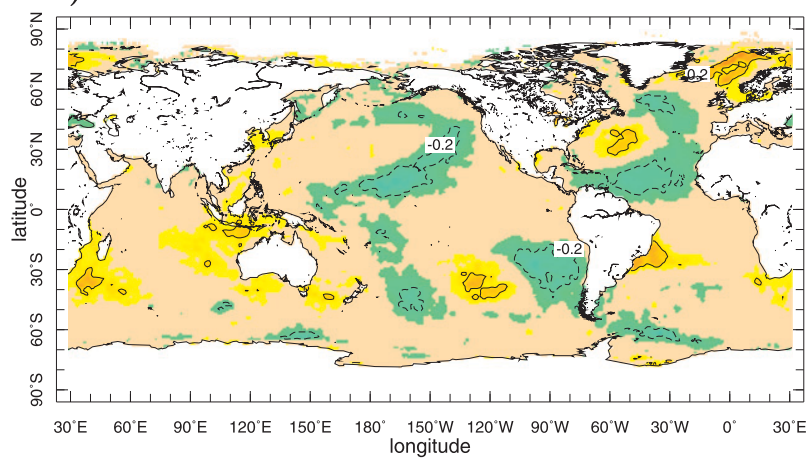

c) $\mathrm{SON}$

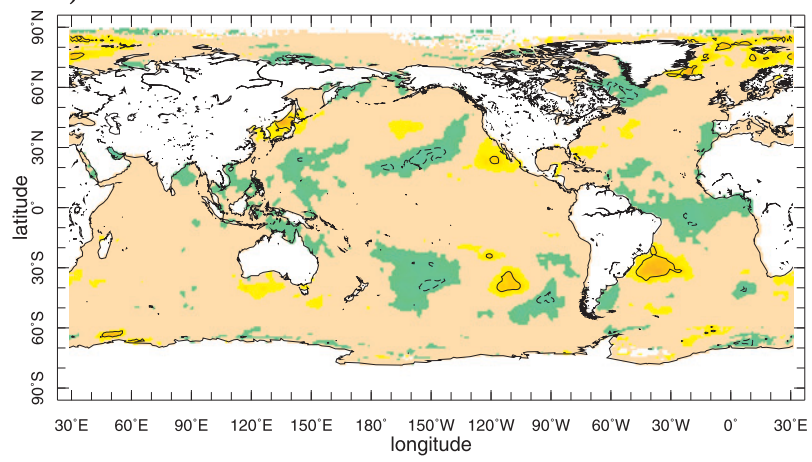

b) JJA

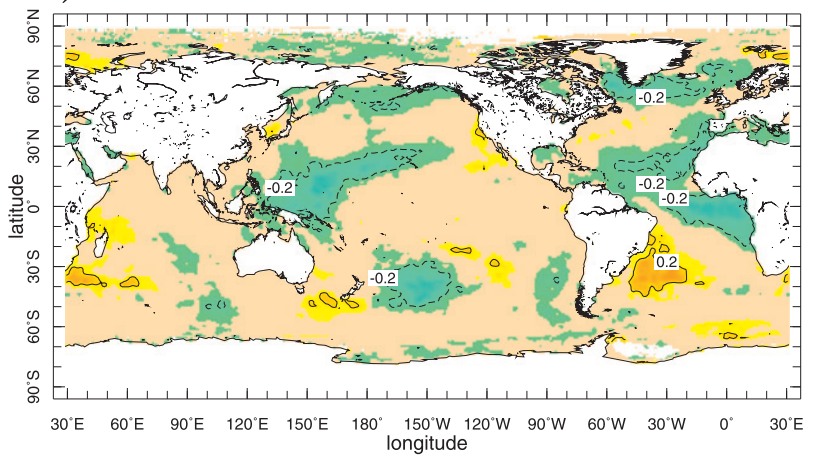

d) DJF

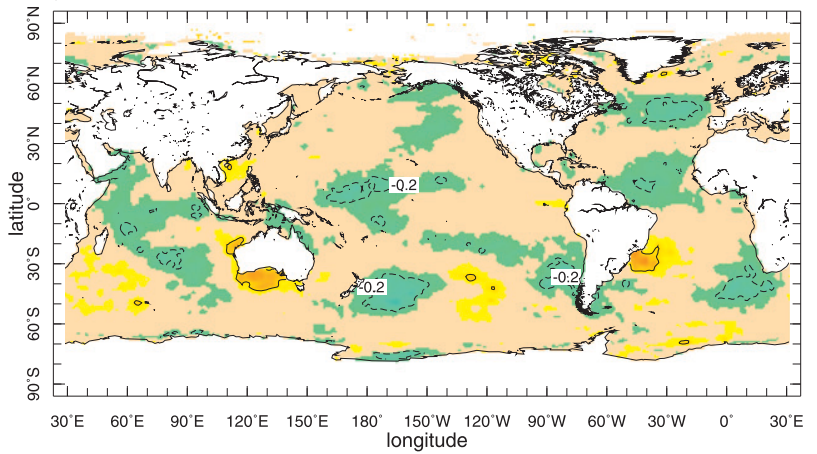

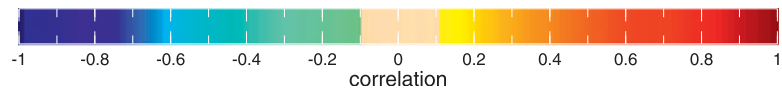

FIG. 5. Correlation between observed SESA precipitation, after the influence of ENSO and a linear trend have been removed, and global SSTs by season for 1901-2007.

force Rossby wave teleconnections and a wave pattern arching southeastward from the equatorial Pacific Ocean to South America. This tends to create a barotropic low over SESA during El Niños that presumably is linked to the increased precipitation. Here we will focus on the less studied link between tropical Atlantic SST anomalies and SESA precipitation.

To further set the stage, Fig. 10 shows the correlation of precipitation across South America on the tropical Atlantic SST index after all data have been detrended and ENSO removed by linear regression, by season, for both observations and the GOGA model. The observations show warm tropical Atlantic SSTs associated with wetness over northeastern South America and dryness over extratropical South America, with the exception of wetness at the very southern tip of the continent. The observed correlations are low but reach statistical significance in the JJA season. The GOGA-modeled spatial pattern is very similar in all seasons, and the correlations are higher, as expected given that it is for the ensemble mean, and lend support to the contention that the tropical Atlantic-SST-SESA precipitation link is real.
The methodology employed to understand the tropical Atlantic influence is a large ensemble of 100-daylong integrations of a GCM in which a SST anomaly is instantaneously turned on at the beginning of the first day. The SST anomaly corresponds to that derived by regression of June-August mean SST onto the GOGA modeled, ENSO-removed SESA precipitation index for June-August. For the cold tropical Atlantic experiments, we only use the negative part of this pattern between $20^{\circ} \mathrm{N}$ and $20^{\circ} \mathrm{S}$. A companion ensemble is generated with the opposite signed SST anomaly. Climatological SSTs are retained outside of the tropical Atlantic region except that a 75-m-deep mixed layer is placed in the part of the South Atlantic Ocean south of the forcing region. This is done to examine if the warm SST anomalies there during times when SESA is wet can be generated through the atmosphere as a response to cold tropical Atlantic SST anomalies. In the mixed layer ocean region SST anomalies develop in response to surface heat flux anomalies. The surface heat flux anomalies are calculated on a day-to-day basis as the difference between the surface heat flux in the run with anomalous SST forcing and the 
a) MAM

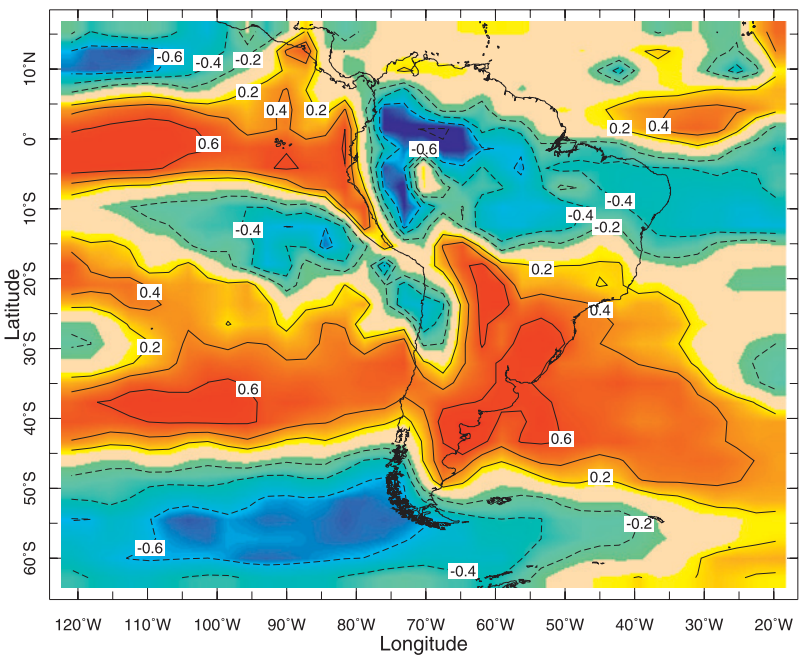

c) $\mathrm{SON}$

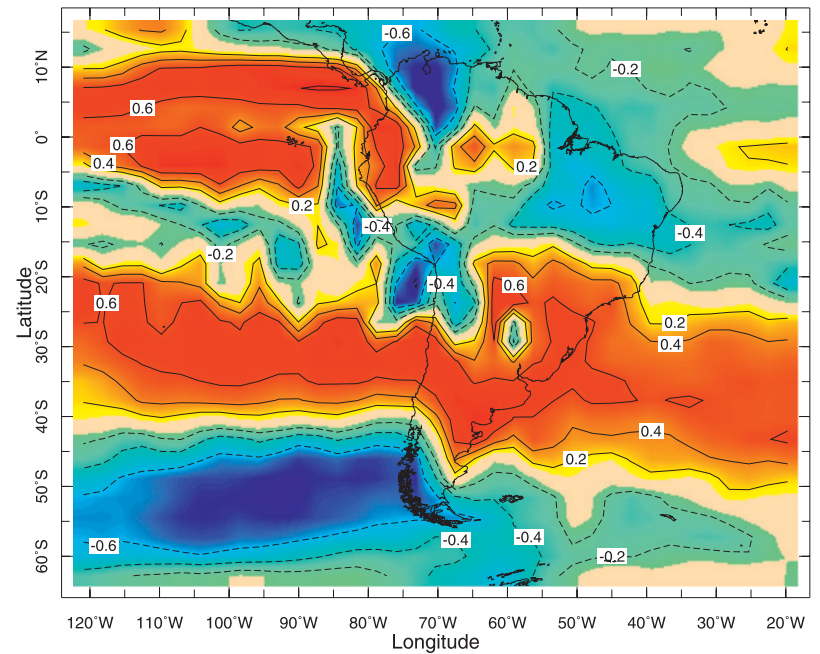

b) JJA

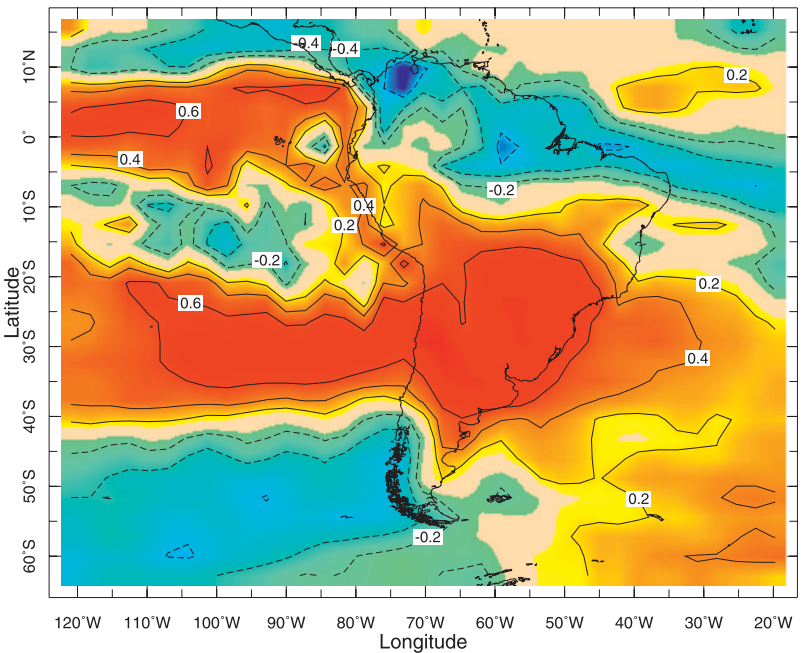

d) DJF

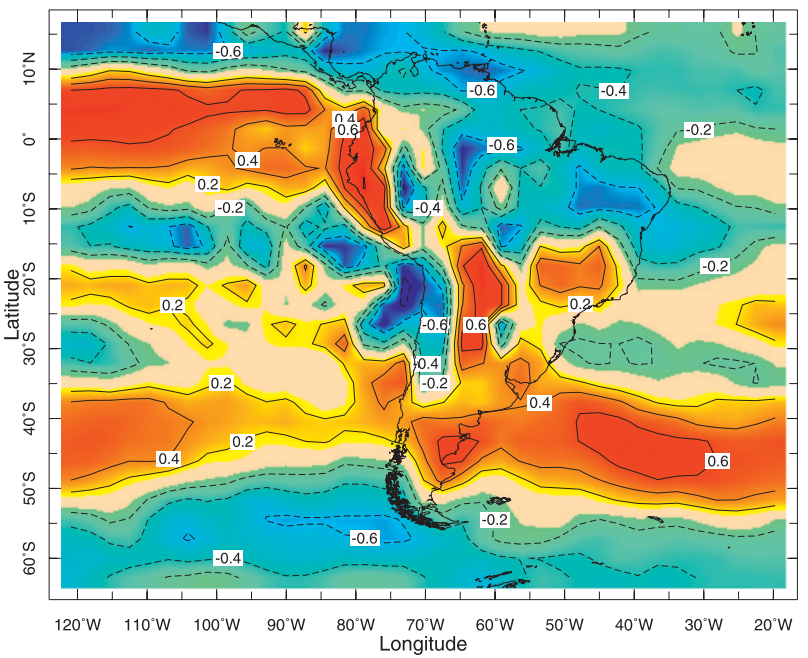

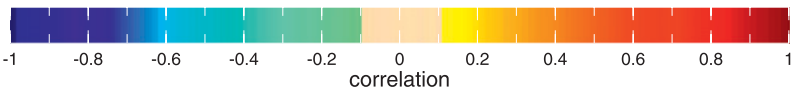

FIG. 6. Correlation between GOGA-modeled precipitation and the TP SST index by season for 1901-2007.

ensemble mean of another 100 simulations with climatological SST forcing. Each of the 100 members of the ensemble is begun with different initial conditions for 1 June, taken from other runs of the atmosphere GCM. Daily data are saved, and the results presented are for the mean of the 100-member ensemble.

Within the time scale of initial value predictability (one to two weeks), the solutions within the ensemble vary little and, comparing the two ensemble means on a day-by-day basis, reveal a clean evolution of the circulation and precipitation in response to the SST forcing. On longer time scales the solutions within the ensemble begin to differ as a result of chaos: time averaging is also needed to isolate the SST anomaly-forced signal. This methodology has previously been used in Seager et al. (2009b) to examine the response over Mexico, Central America, and the Intra-America Seas to Northern Hemisphere summer-season ENSO anomalies.

In Fig. 11 we present the ensemble mean of the cold tropical Atlantic SST anomaly experiment minus the ensemble mean of the warm anomaly experiment for the precipitation (colors) and 200-mb height (contours) for individual days and for the 100-day mean. Precipitation quickly decreases over the cold tropical Atlantic waters, and upper-tropospheric low pressure develops centered on the equator to the east and off the equator to the 
a) MAM

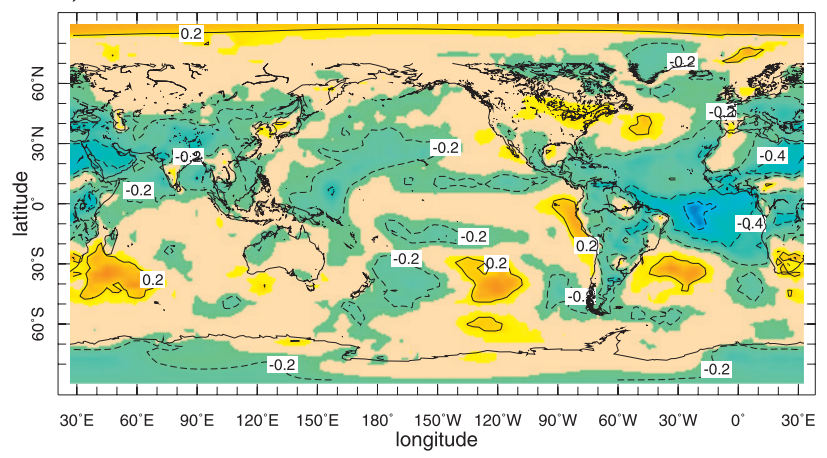

c) $\mathrm{SON}$

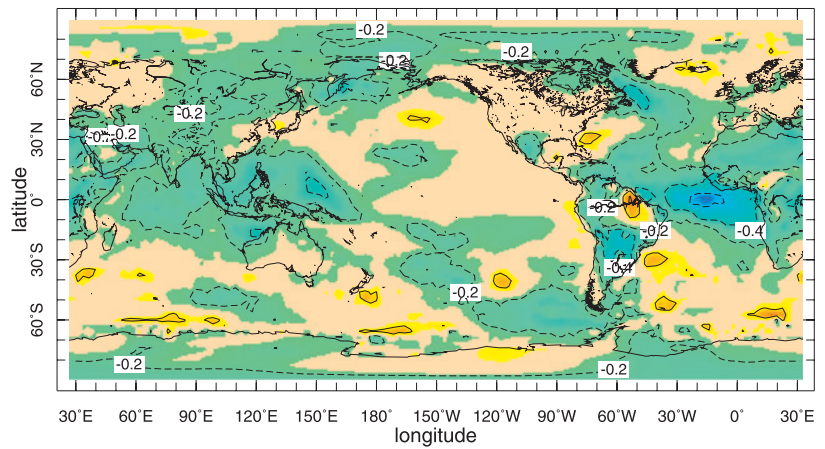

b) JJA

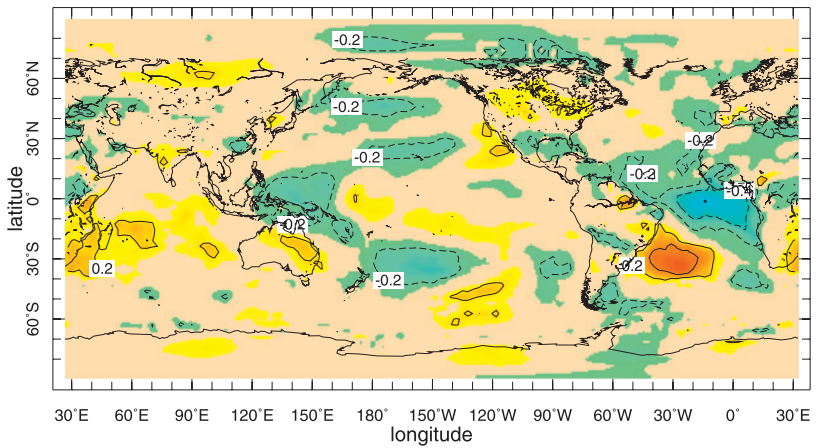

d) DJF

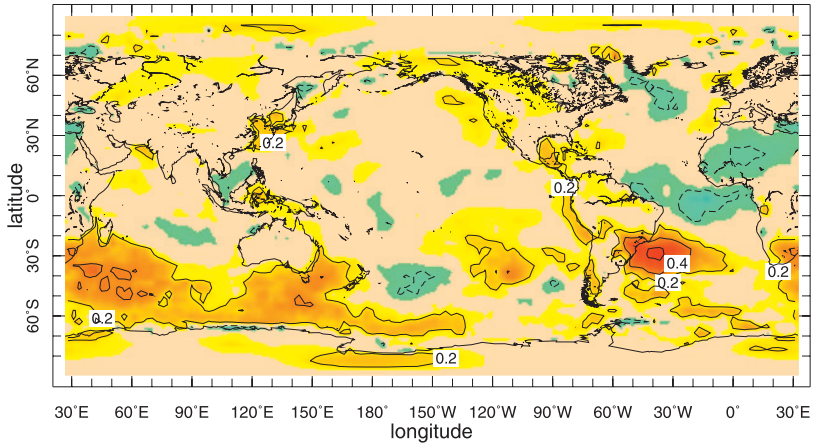

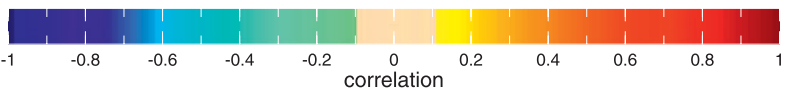

FIG. 7. Correlation between GOGA-modeled SESA precipitation, after the influence of ENSO has been removed, and global surface temperature by season for 1901-2007.

west. This is as in the Gill (1980) linear Kelvin and Rossby wave response to tropical heating anomalies. By day 5 a wave train begins to develop south-southeastward from northern South America, creating upper-tropospheric high pressure over the southwest South Atlantic Ocean at about $50^{\circ} \mathrm{S}$. Beginning on day 3 and developing over the subsequent several days, there is a region of increased precipitation over subtropical South America centered at about $20^{\circ}-30^{\circ} \mathrm{S}$.

Figure 12 shows the day-by-day evolution of $700-\mathrm{mb}$ vertical pressure velocity (upward corresponds to negative values) and the vertically integrated moisture divergence from these simulations. Downward motion quickly develops along with moisture divergence over the cold tropical Atlantic SST anomalies. In subsequent days upward motion develops to the southwest of the tropical Atlantic heating anomaly along with anomalous moisture convergence, included over the South American continent in a band centered at about $30^{\circ} \mathrm{S}$. Although these anomalies are noisy, in general, anomalous upward motion and moisture convergence match the areas of increased precipitation seen in Fig. 11.
These results indicate that, to understand why cold tropical Atlantic SST anomalies induce increased precipitation over SESA, we need to understand why they induce anomalous upward motion in the area. To do that we analyze the day-by-day evolution of the $200-\mathrm{mb}$ vorticity budget, written as

$$
\begin{aligned}
& \frac{\partial \zeta^{\prime}}{\partial t}+\mathbf{u}^{\prime} \cdot \nabla \bar{\zeta}+\overline{\mathbf{u}} \cdot \nabla \zeta^{\prime}+(\bar{\zeta}+f) \nabla \cdot \mathbf{u}^{\prime}+\zeta^{\prime} \nabla \cdot \overline{\mathbf{u}} \\
& \quad+\nabla \cdot\left(\mathbf{u}^{\prime \prime} \zeta^{\prime \prime}\right)^{\prime}+\beta v^{\prime}=F^{\prime} .
\end{aligned}
$$

Here $\zeta$ is relative vorticity, $\mathbf{u}$ is the vector flow, $f$ is the Coriolis parameter and $\beta$ its meridional derivative, and $F$ is damping. The overbars indicate the average of the cold tropical Atlantic and warm tropical Atlantic simulations, and the primes indicate the cold Atlantic simulation minus the warm Atlantic simulation. All fields are low-pass Butterworth filtered to remove variations on less than 8 -day time scales, and the doubleprimed quantities are the high-pass filtered variables, which combine to give a transient-eddy vorticity flux convergence. 

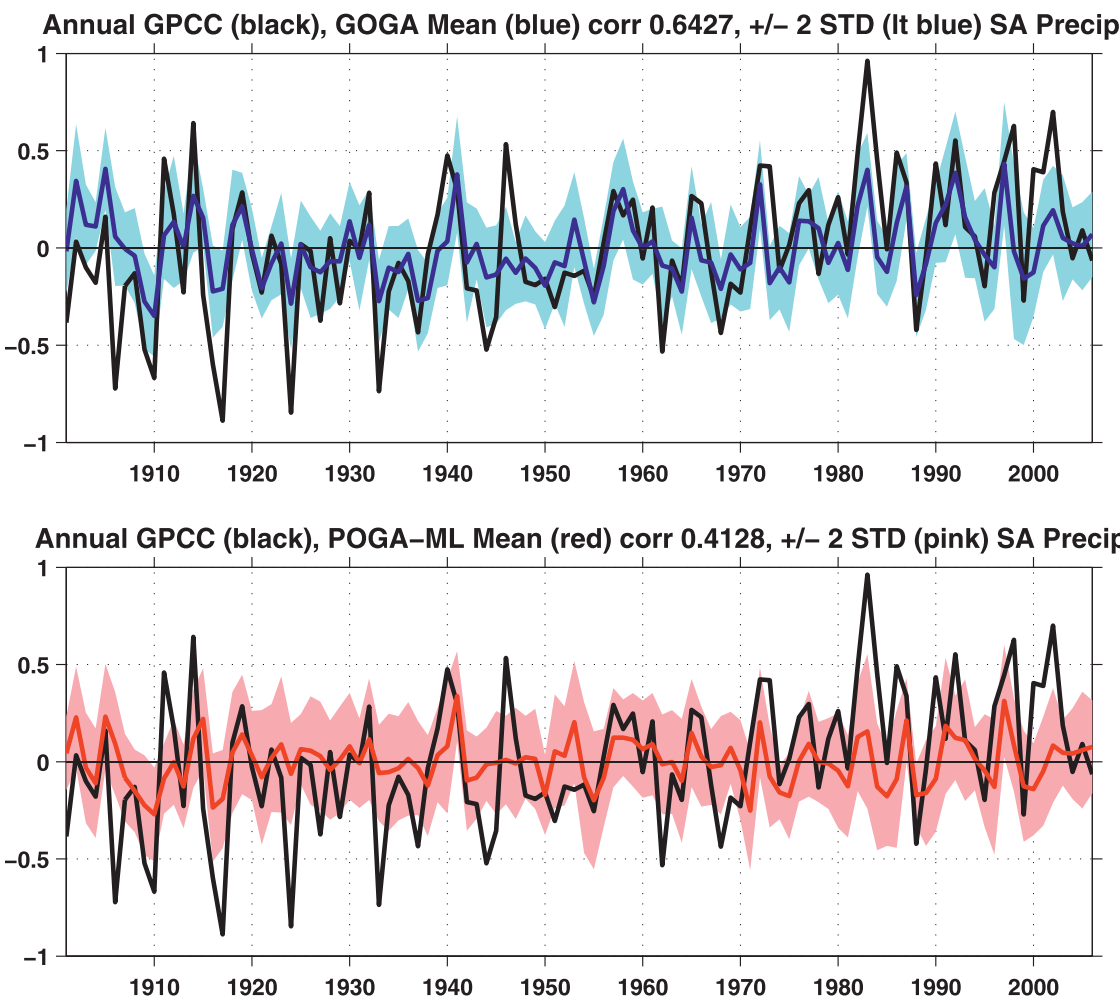

FIG. 8. Time history of annual mean SESA precipitation for GPCC observed and the (top) GOGA-modeled ensemble mean and (bottom) POGA-ML ensemble mean for the 1901-2007 period. Units are $\mathrm{mm}^{\mathrm{day}}{ }^{-1}$.

After all terms had been evaluated, it was found by inspection that, for the tropical Atlantic and SESA region of interest, the stretching term involving the anomalous vorticity and the mean divergence, $\zeta^{\prime} \nabla \cdot \overline{\mathbf{u}}$; the transient-eddy vorticity convergence anomaly, $\nabla \cdot\left(\mathbf{u}^{\prime \prime} \zeta^{\prime \prime}\right)^{\prime}$; and the damping anomaly were negligible compared to the order of magnitude of the other terms. Thus, Eq. (1) can be simplified to

$\frac{\partial \zeta^{\prime}}{\partial t}+\left(\mathbf{u}^{\prime} \cdot \nabla \bar{\zeta}+\overline{\mathbf{u}} \cdot \nabla \zeta^{\prime}\right)+(\bar{\zeta}+f) \nabla \cdot \mathbf{u}^{\prime}+\beta v^{\prime}=0$

The time evolution of the upper-tropospheric flow, plotted together with the mean absolute vorticity, is shown in Fig. 13. The upper-level cyclone centered south of the tropical Atlantic heating anomaly is clearly visible along with the southerly flow over South America, north of $30^{\circ} \mathrm{S}$, on its western flank. The contribution of the relative vorticity to the absolute vorticity is shown by the departure of the contours from lines of latitude and the creation of areas of strong and weak vorticity gradients. The anomalous southerly flow over South America at about $20^{\circ} \mathrm{S}$ flows across a strong vorticity gradient, creating a large vorticity tendency that needs to be balanced by another term in the vorticity equation.
The four dominant terms in the vorticity budget, with the two advection terms grouped together, for days 3 and 7 are shown in Fig. 14. The cold SST anomalies create a negative atmospheric heating perturbation that is balanced by anomalous downward flow and, hence, upperlevel convergence. Since $\beta$ is positive everywhere, the meridional flow within this convergence pattern is shown in the panel for $\beta v^{\prime}$ and has mostly southerly flow over the Southern Hemisphere and northerly flow in the Northern Hemisphere, to the west of the heating anomaly and the opposite east of the heating anomaly. This is associated with the characteristic "Gill-type" response with upperlevel cyclones symmetric about the equator centered west of the heating anomaly, contained within a Rossby wave response, and easterly winds to the east, contained within a Kelvin wave response.

The solution departs from the Gill (1980) response in that the advection of relative vorticity by the mean and anomalous flow is also important. Examining the magnitude of the individual terms within the model solution suggests that Eq. (2) can be simplified further as

$$
\frac{\partial \zeta^{\prime}}{\partial t}+v^{\prime} \frac{\partial \bar{\zeta}}{\partial y}+\bar{u} \frac{\partial \zeta^{\prime}}{\partial x}+(\bar{\zeta}+f) \nabla \cdot \mathbf{u}^{\prime}+\beta v^{\prime}=0
$$


Det. Std. Annual SESA - ENSO (solid) and Tropical Atlantic * -1 (dashed)

a) GOGA corr 0.65

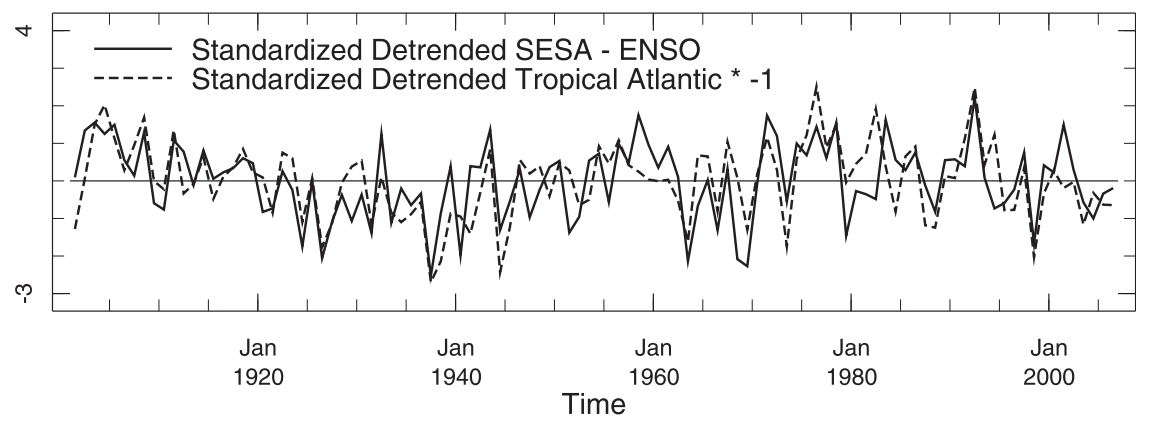

b) GPCC Precip and Hadley SSTA corr 0.27

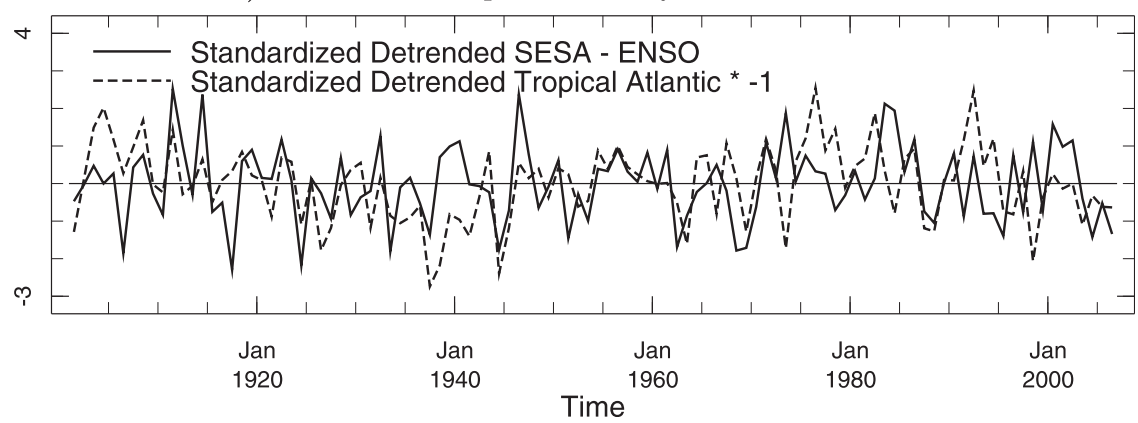

FIG. 9. (top) Time history of GOGA-modeled ENSO-removed SESA precipitation (solid) and the detrended tropical Atlantic SST index (dashed) multiplied by -1 and (bottom) the same but for observed GPCC precipitation. All time series have been standardized.

The meridional gradient of mean relative vorticity is positive in the region of the southern subtropical jet and weakly negative north of the jet. The zonal gradient of anomalous relative vorticity is negative in the Southern Hemisphere west of the cyclone center and positive east of it, both in regions of mean westerlies. Hence, over subtropical South America, southwest of the center of the tropical heating anomaly and north of the mean jet, $v^{\prime} \bar{\zeta}_{y}+\bar{u} \zeta_{x}^{\prime}$ is negative and can balance $\beta v^{\prime}$ with some contribution from the stretching term. Farther south, over SESA where the meridional gradient of mean relative vorticity is positive and the zonal gradient of anomalous relative vorticity becomes small, the tropical directly forced $v^{\prime}$ means that $v^{\prime} \bar{\zeta}_{y}$ and $\beta v^{\prime}$ combine to force negative $(\bar{\zeta}+f) \boldsymbol{\nabla} \cdot \mathbf{u}^{\prime}$. This requires upper-level divergence and, hence, vertical motion.

Consequently, via the vorticity balance, we see how the cold tropical Atlantic SST anomaly induces ascent to its southwest: 1) the cold SST and negative tropical heating anomaly induce upper-level convergence and southerly flow to the southwest, 2) over South America between $20^{\circ} \mathrm{S}$ and $40^{\circ} \mathrm{S}$ the advection of absolute vorticity by the southerly flow requires vortex stretching and ascent to balance, and 3) the ascent causes increased precipitation. To the southeast of the tropical heating anomaly, over the southeast Atlantic Ocean and on the eastern flank of the cyclone, $v^{\prime}$ is southward and descent/ subsidence is induced by the $v^{\prime} \bar{\zeta}_{y}$ and $\beta v^{\prime}$ terms. The vertical motion anomalies are key to explaining the precipitation anomalies since ascent is required to convert water vapor to condensate and, ultimately, precipitation. In places such as SESA, when the tropical Atlantic is cold, where the dynamics induce ascent, there is increased precipitation, while to the east, where descent/subsidence is induced, precipitation is suppressed.

In response to cold tropical Atlantic SST anomalies the circulation creates not only wet conditions over SESA but also warms the southwest South Atlantic Ocean, where the mixed layer is used, via a reduction in latent heat flux cooling (not shown). However, the SST anomalies are a fraction of a degree centigrade and smaller than those observed in this region, perhaps because the mixed layer is too deep, neglect of anomalous Ekman advection, or the 100-day integrations are too short for the SST anomalies to fully form. However, this suggests that the association between a wet SESA and warm SST anomalies in this region is not necessarily causal and that the SST anomalies could be generated as a response to cold tropical Atlantic SST anomalies. 
Observed
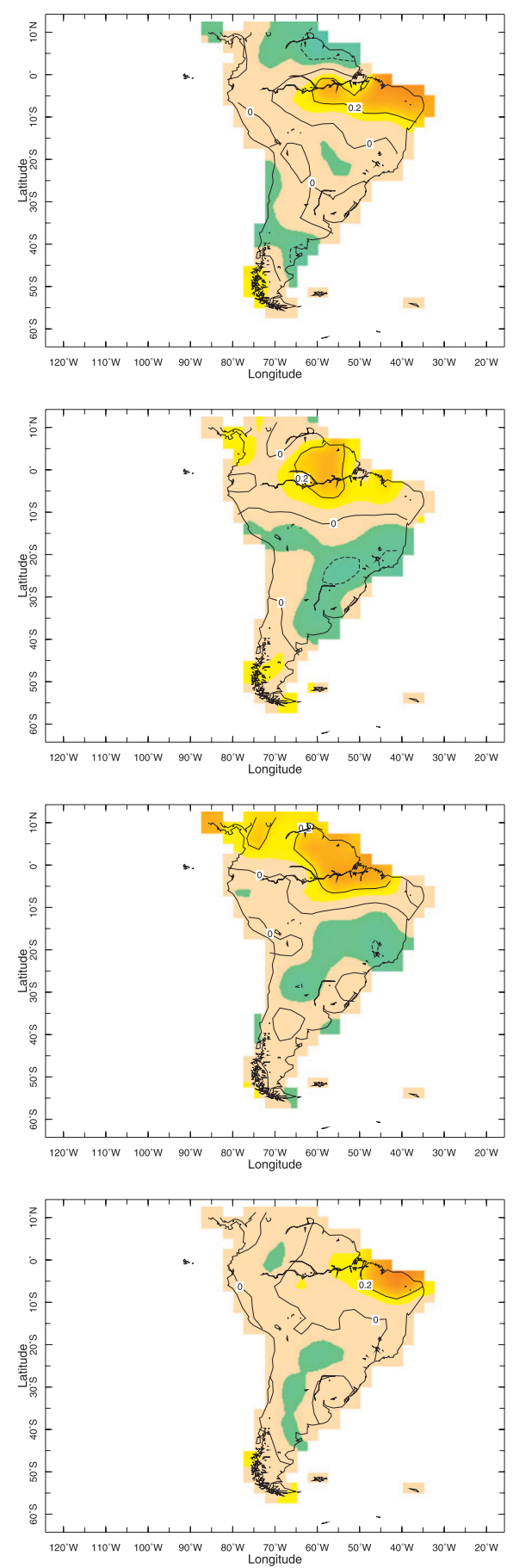

\section{GOGA}

MAM

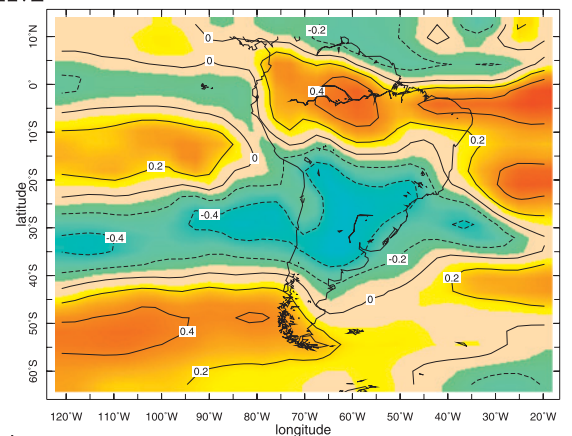

JJA

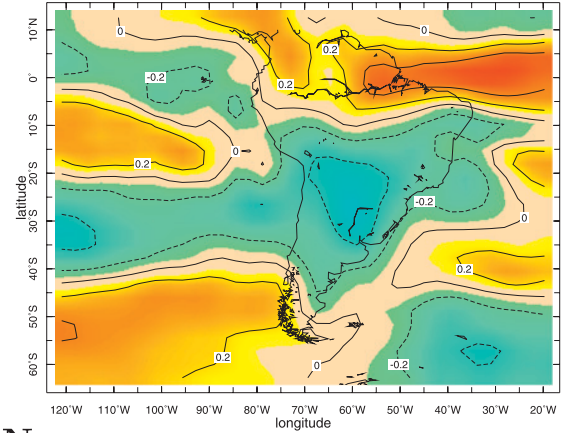

SON

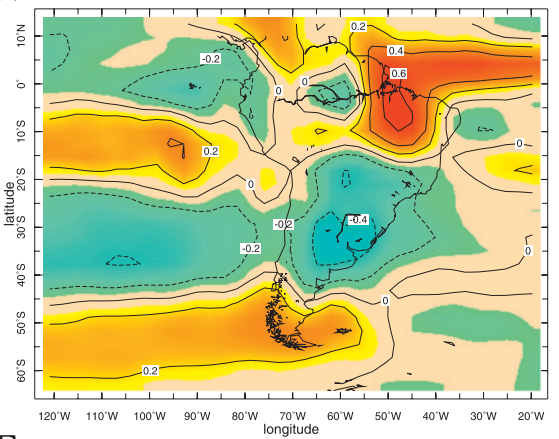

DJF

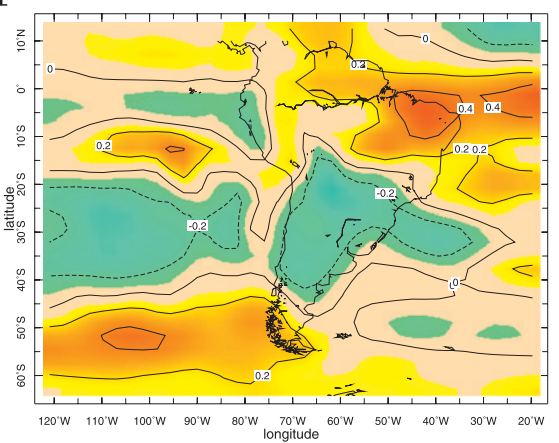

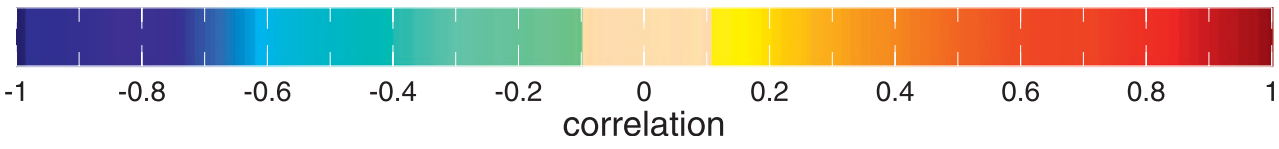

FIG. 10. Correlation between (left) GPCC observed and (right) GOGA-modeled precipitation across South America and the tropical Atlantic SST index, by season for 1901-2007, after all data have been detrended and had their ENSO influence removed. 
Day 1
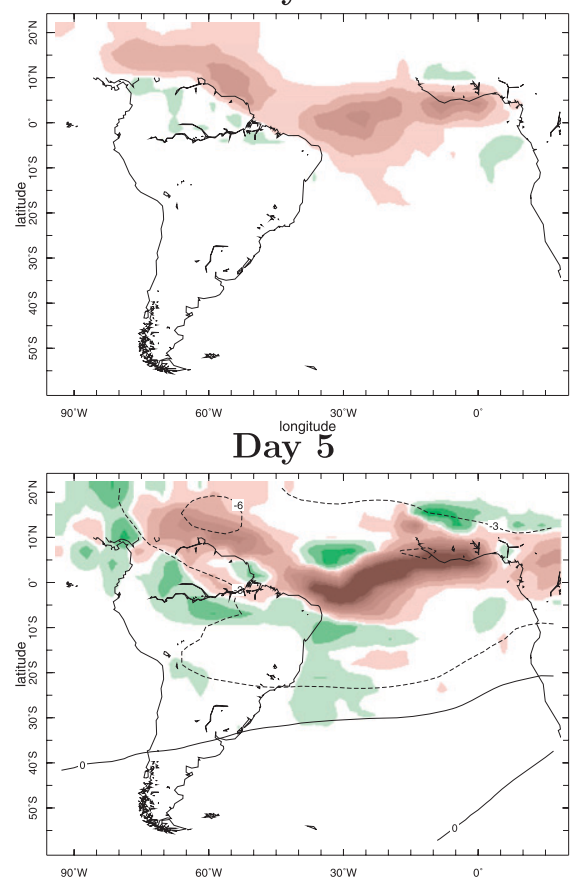

Day 9

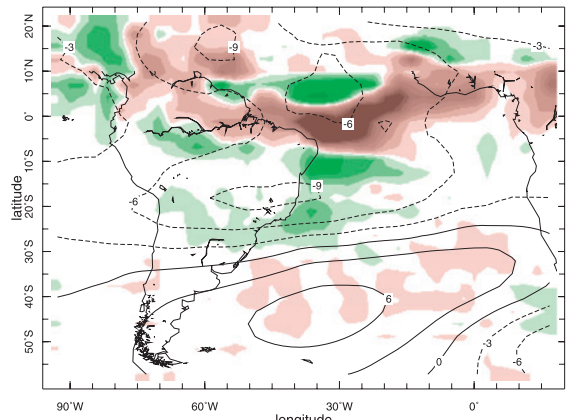

Day 13
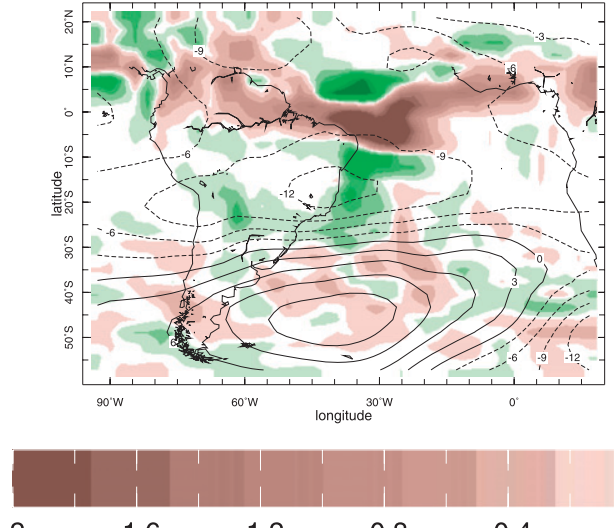

$-1.6$

\section{$-1.2$}
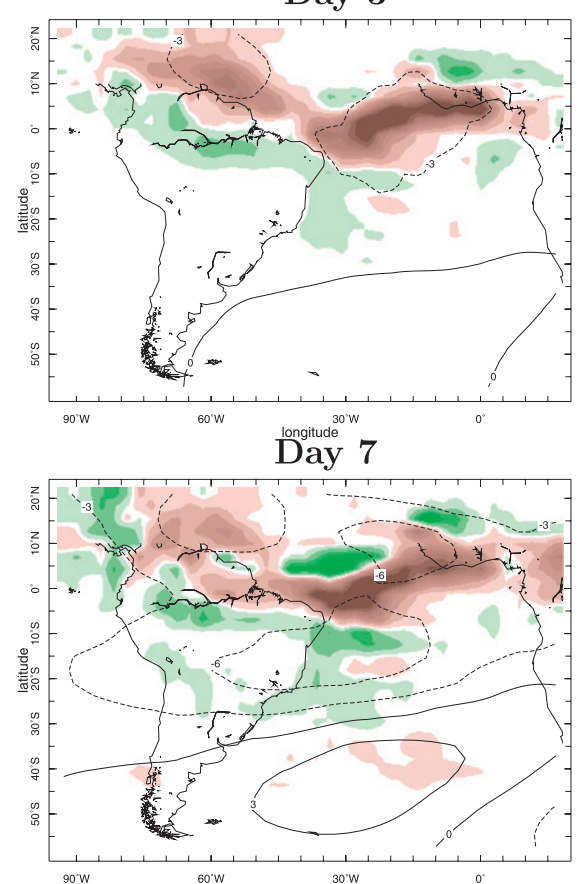

Day 11

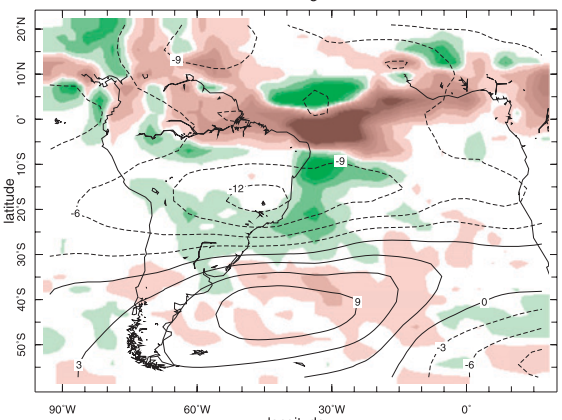

100 Day Average
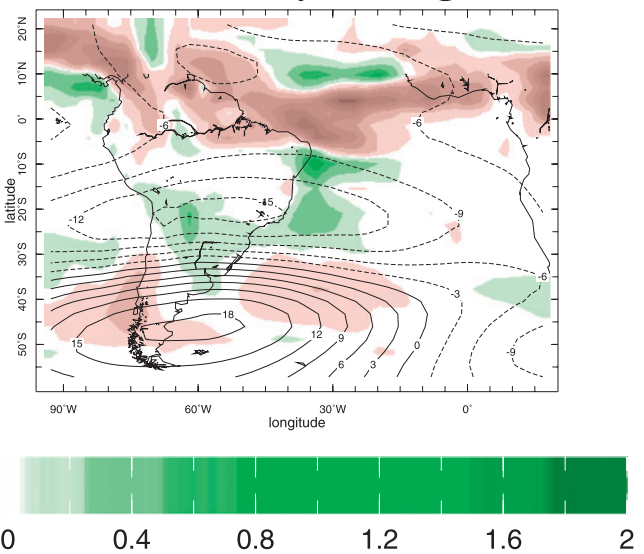

Precip (colors) Heights (contours every 3$)$ []

FIG. 11. The 200-mb height anomaly (contours) and precipitation anomaly (colors) from the simulations with a cold tropical Atlantic SST anomaly minus a warm SST anomaly. Results are the average of 100-member ensembles in which the SST anomalies are instantaneously applied on 1 Jun and run for 100 days and are shown for days $1,3,5,7,9,11$, and 13 and the 100 -day average. Units are $\mathrm{mm} \mathrm{day}^{-1}$ for precipitation and meters for geopotential height. 
Day 1
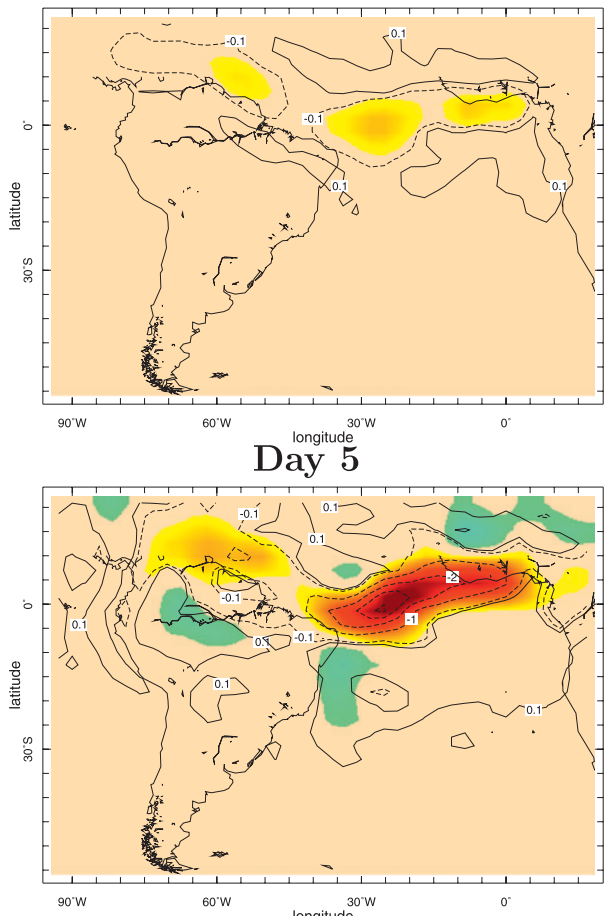

Day 9

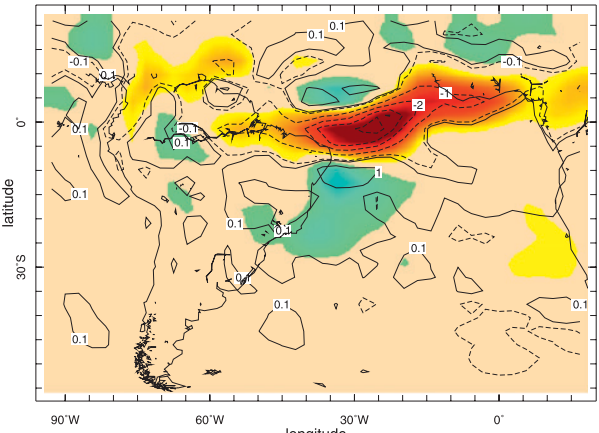

Day 13

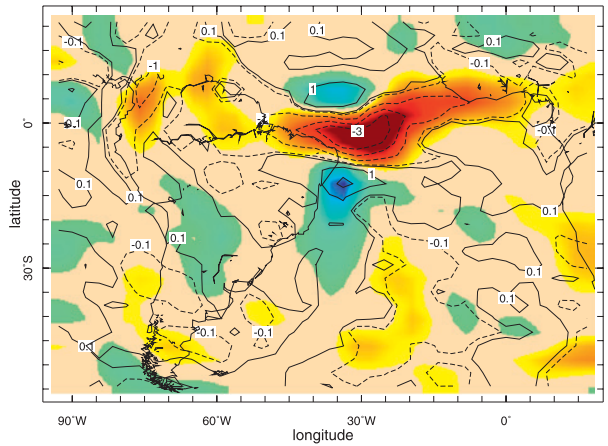

Day 3
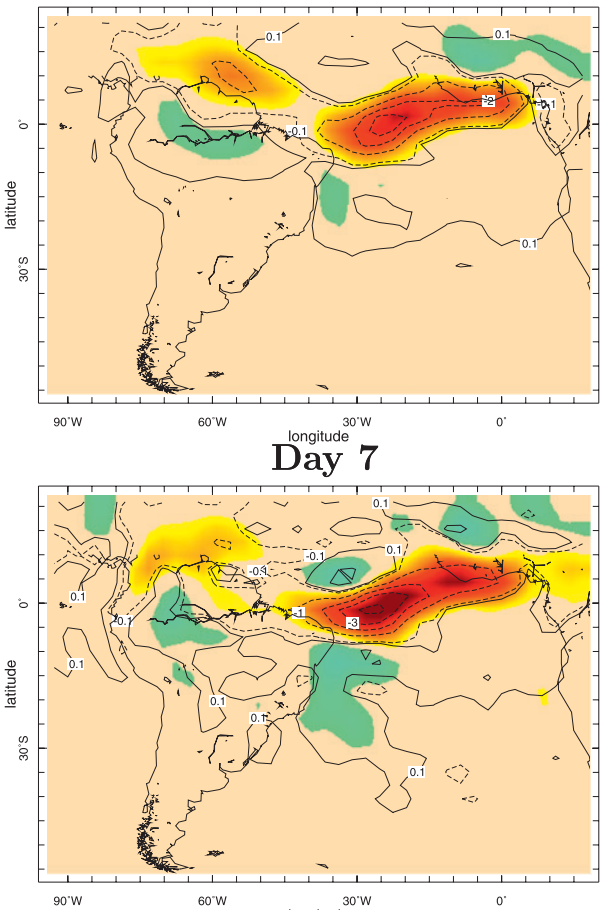

Day 11

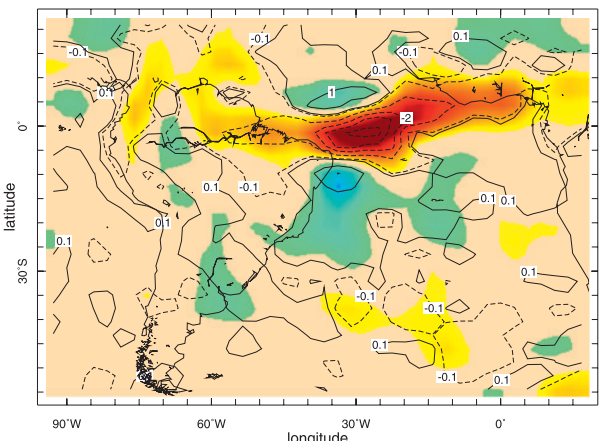

100 Day Average

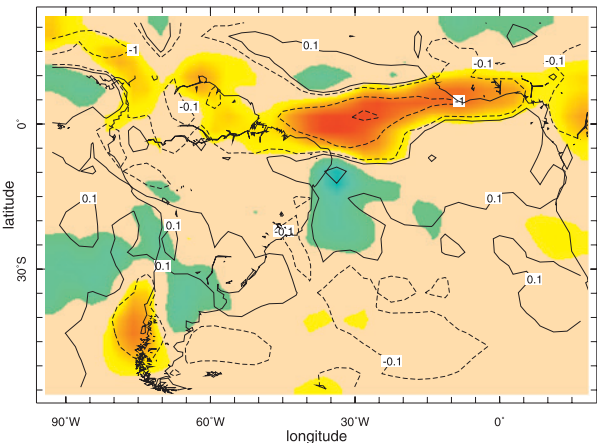

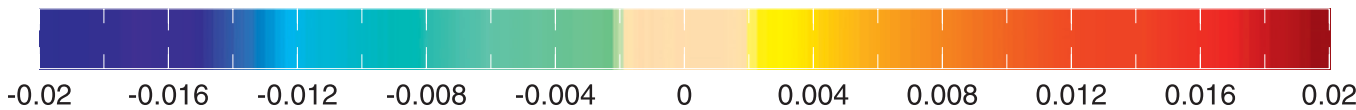

Vert Vel (color Pa/s), Vert Int Moisture Conv (contours $-3,-2,-1,-0.1,0.1,1,2$, and $3 \mathrm{~mm} /$ day) []

FIG. 12. As in Fig. 11, but for the vertical pressure velocity at $700 \mathrm{mb}$ (colors) and the vertically integrated moisture convergence (contours). Units are $\mathrm{Pa} \mathrm{s}^{-1}$ for velocity and $\mathrm{mm}_{\text {day }}{ }^{-1}$ for moisture convergence. 
day 1

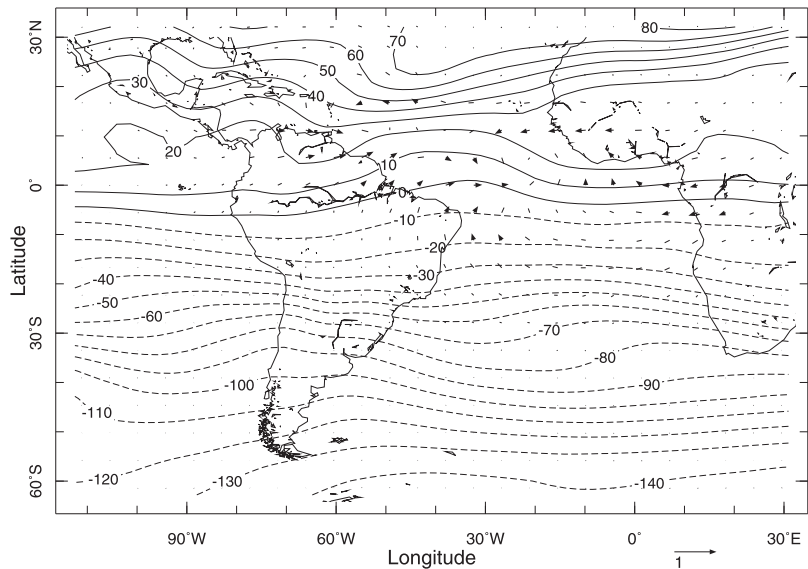

day 5

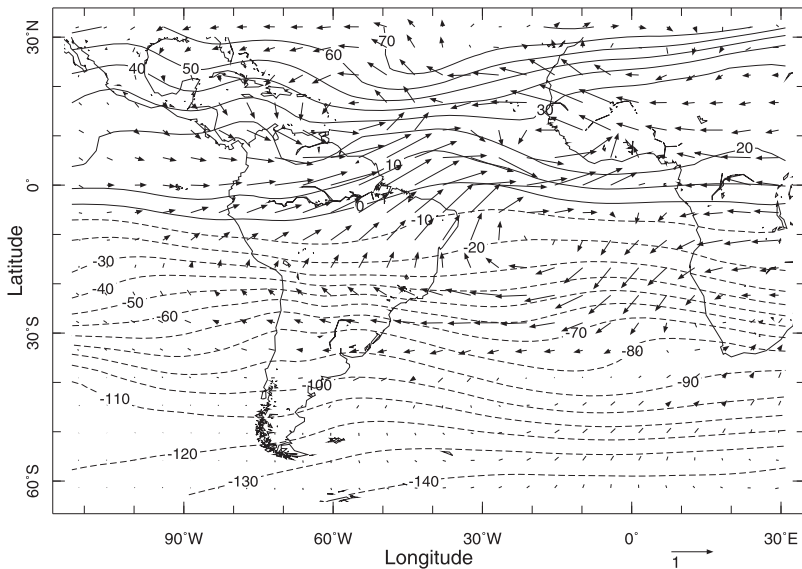

day 9

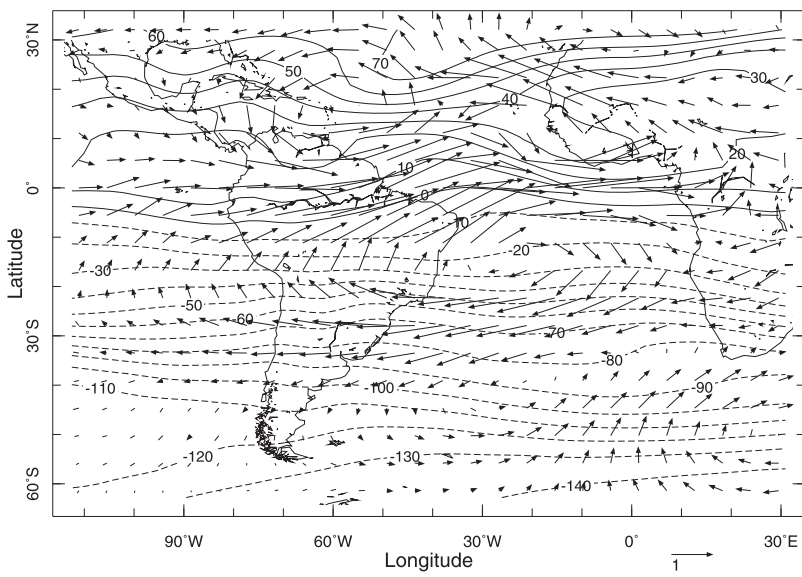

day 3

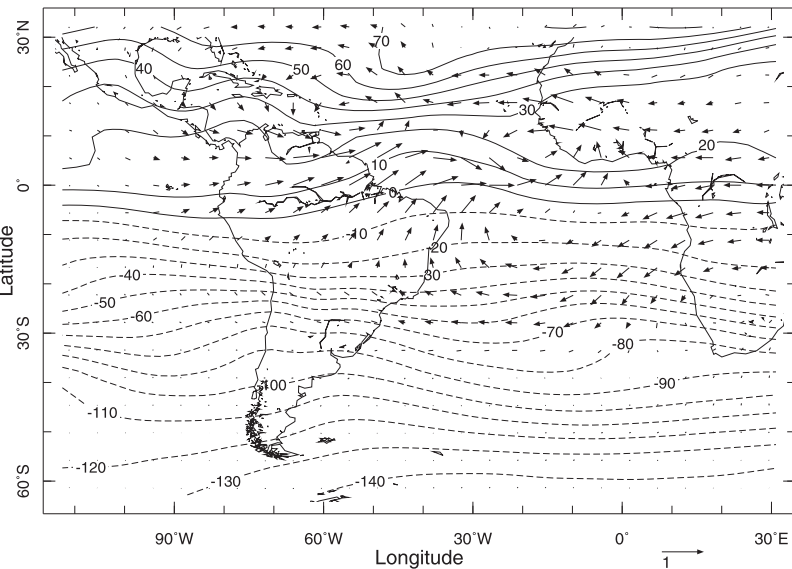

day 7

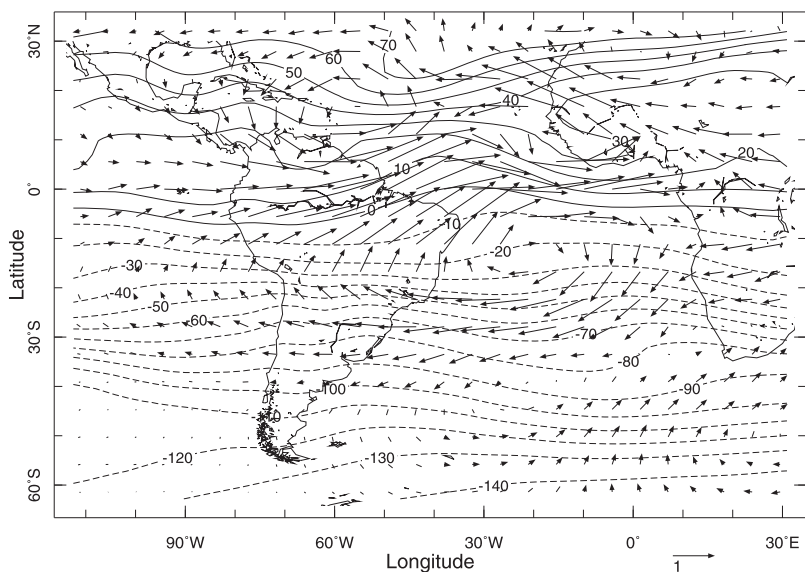

100 day average

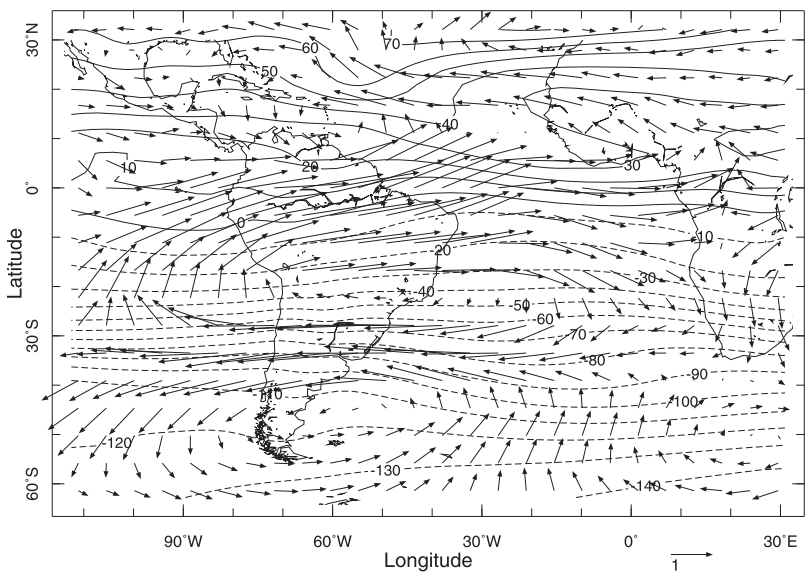

FIG. 13. The flow at $200 \mathrm{mb}$ from the simulations with a cold tropical Atlantic SST anomaly minus a warm SST anomaly and the mean absolute vorticity. Results are the average of 100-member ensembles in which the SST anomalies are instantaneously applied on 1 Jun and run for 100 days and are shown for days 3 and 7 . Vector winds are in $\mathrm{m} \mathrm{s}^{-1}$, and the vorticity has been multiplied by $10^{11}$. 


\section{day 3}
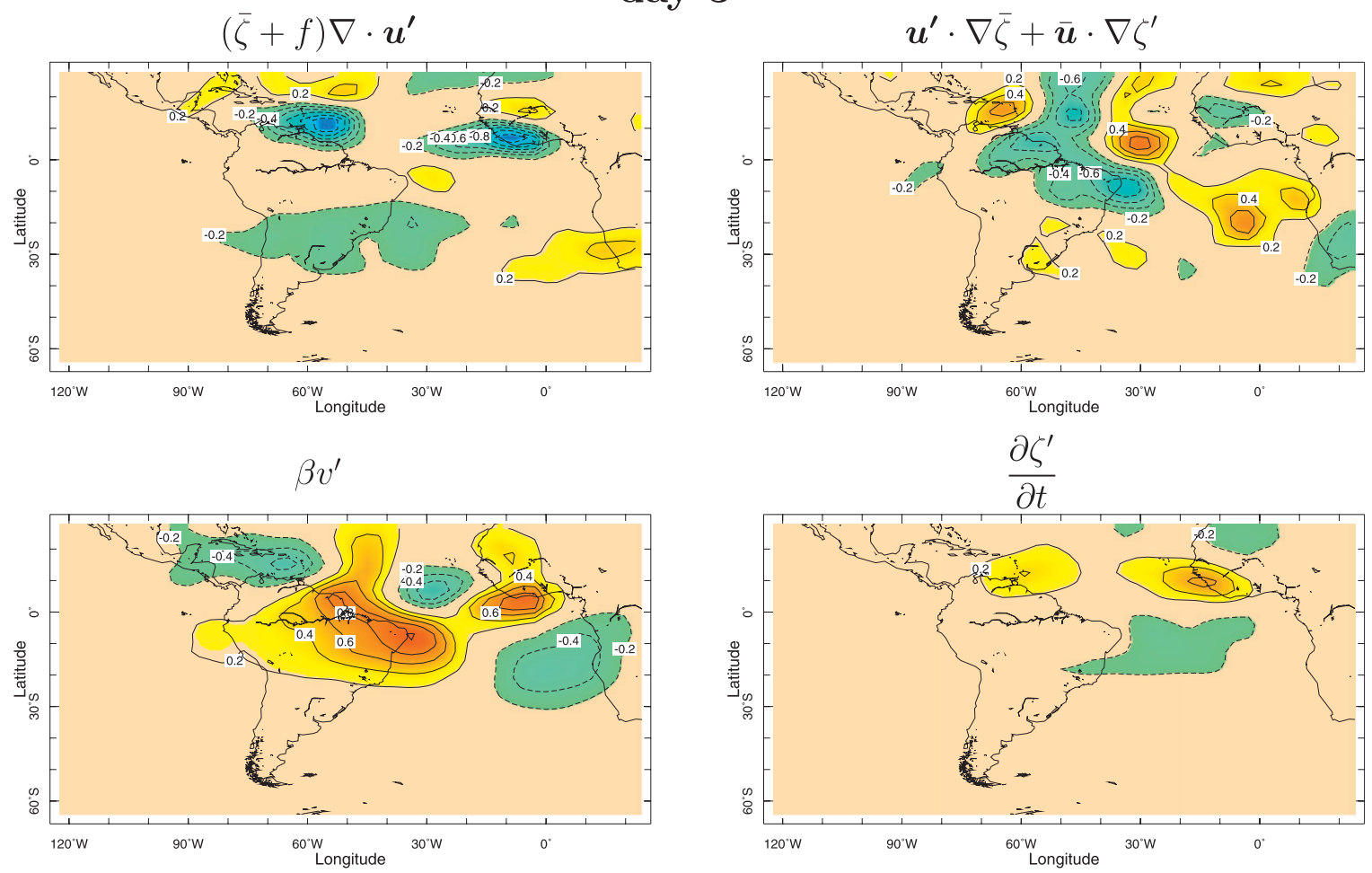

\section{day 7}
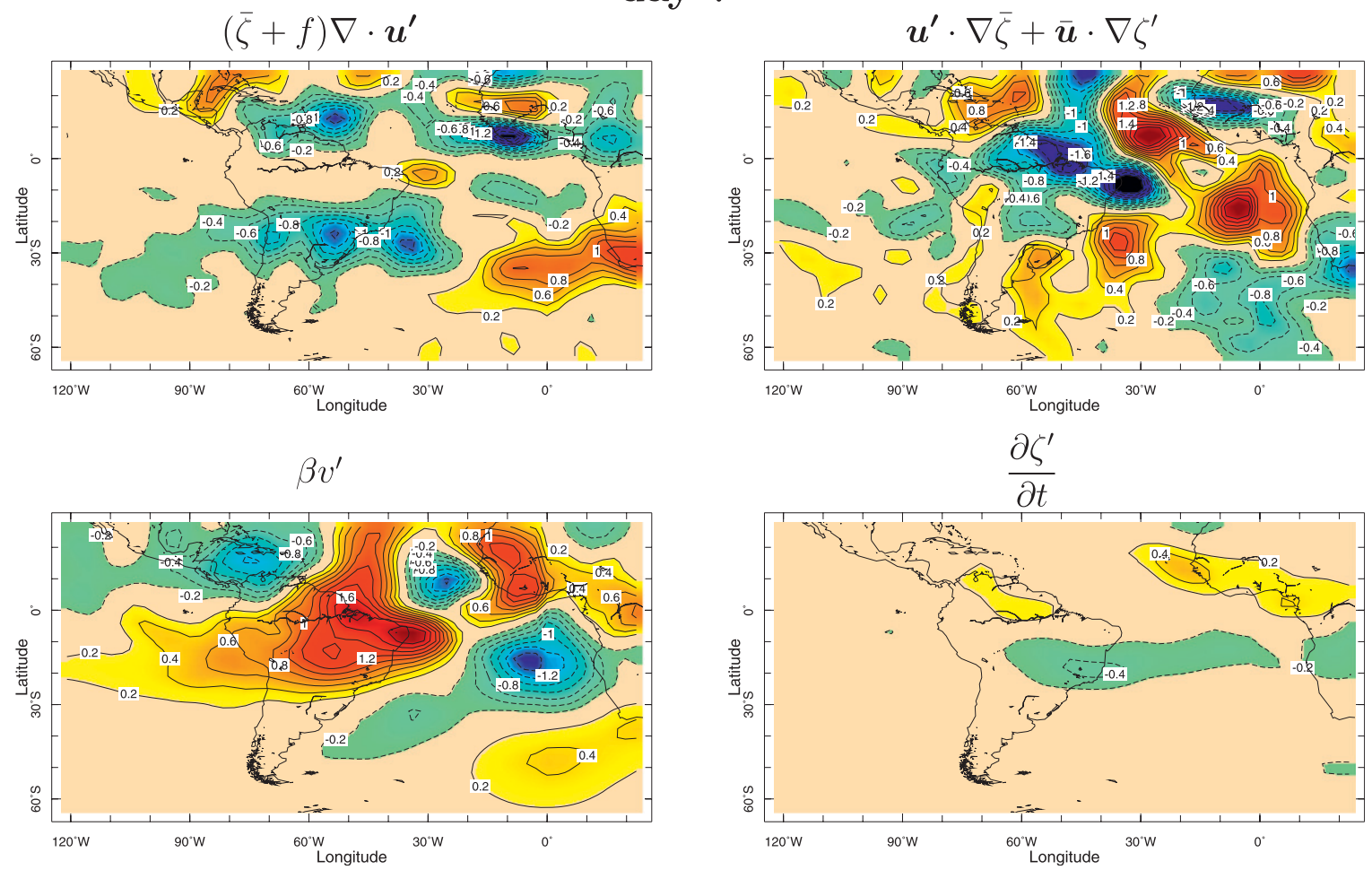

FIG. 14. Vorticity budget terms at $200 \mathrm{mb}$ from the simulations with a cold tropical Atlantic SST anomaly minus a warm SST anomaly. Results are the average of 100-member ensembles in which the SST anomalies are instantaneously applied on 1 Jun and run for 100 days and are shown for days 3 and 7 . Units are $\mathrm{s}^{-2}$, and the terms have been multiplied by $10^{11}$. 
(a) Detrended corr 0.70

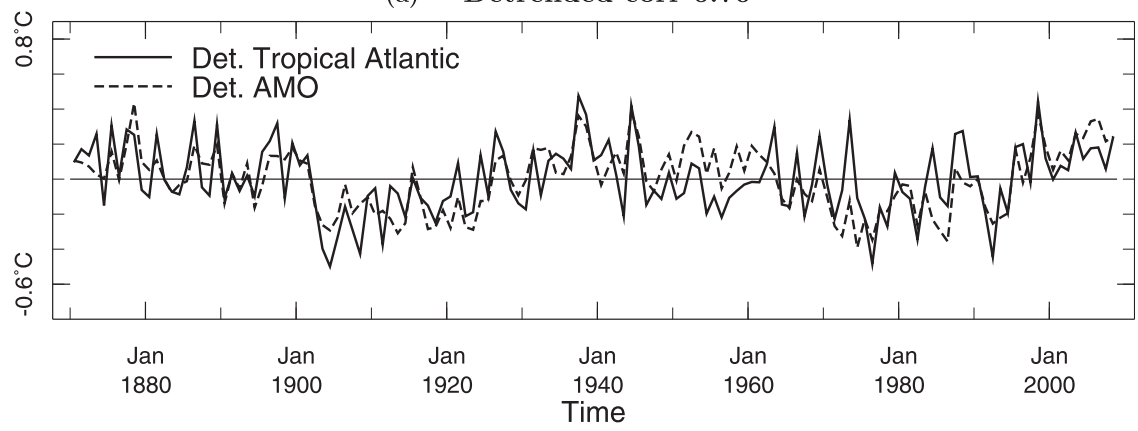

(b) Full corr 0.84

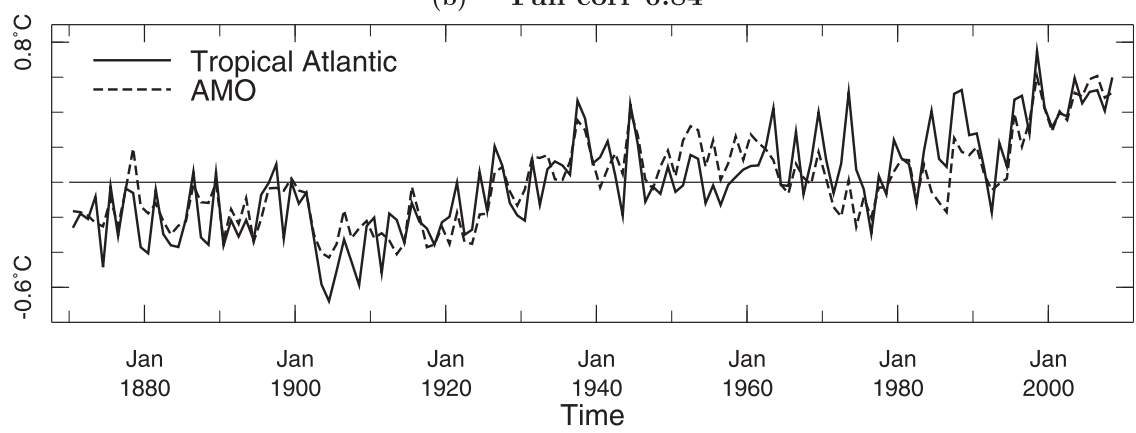

FIG. 15. Time series of the tropical Atlantic SST index (solid) and the Atlantic multidecadal oscillation index (dashed): (top) detrended and (bottom) not detrended. Units are ${ }^{\circ} \mathrm{C}$.

What are the causes of the tropical Atlantic SST anomalies? In Fig. 15 we show time series, both detrended and not detrended, of the tropical Atlantic SST index and the Atlantic multidecadal oscillation (AMO) index (SST averaged over the equator to $60^{\circ} \mathrm{N}$ ). These are very highly correlated, indicating that the tropical SST anomalies vary in phase with SST anomalies across the North Atlantic Ocean. Therefore, we have uncovered evidence of the AMO influencing SESA precipitation and a mechanism for how it does so.

\section{Causes of the 1930s Pampas Dust Bowl drought}

The 1930s drought is of interest because it appears within a hemispherically symmetric pattern of precipitation anomalies across the Americas with drought in both the northern and southern extratropics and wetter conditions in the tropical Americas. In the models, the Pampas Dust Bowl drought is not as robust a feature as the North American Dust Bowl drought. For North America all the GOGA ensemble members produced drier-than-normal conditions averaged from 1932 to 1939 and only a few ensemble members had wet years within the period (Seager et al. 2005b, 2008); however, for South America, several of the ensemble members produce wetter-than-normal years in the 1930s. Indeed, it is only when global SST anomalies are specified that the ensemble mean shows a clear drying signal over SESA in the 1930s. Consequently, unlike the North American Dust Bowl (Schubert et al. 2004b; Seager et al. 2005b, 2008; Cook et al. 2009), the Pampas Dust Bowl does not appear strongly tied to the La Niña conditions in the tropical Pacific Ocean during the 1930s.

Figure 16 (top left) shows the observed anomalies of precipitation across the Americas and the observed $\mathrm{Pa}$ cific and Atlantic SST anomalies (top right) during the 1930s. All data were detrended before computing anomalies, for consistency and to remove the long-term warming of the Atlantic Ocean. The droughts in North and South America are clearly seen, as well as the La Niña conditions in the tropical Pacific Ocean. In addition, the tropical Atlantic Ocean was warm, which, on the basis of the work just reported, would be expected to favor drought in extratropical South America. The GOGA model-simulated 1930s precipitation anomaly is shown in the middle left panel and reproduces well the observed pattern across the Americas. In contrast, the POGA-ML precipitation anomaly (middle right panel) has a strong North American drought but a much less accentuated drought in extratropical South America than in the GOGA model.

Also shown in the lower panels are the modeled 700-mb vertical velocity fields and 200-mb heights. The vertical velocity anomalies show, in the GOGA model, anomalous 


\section{Observed}
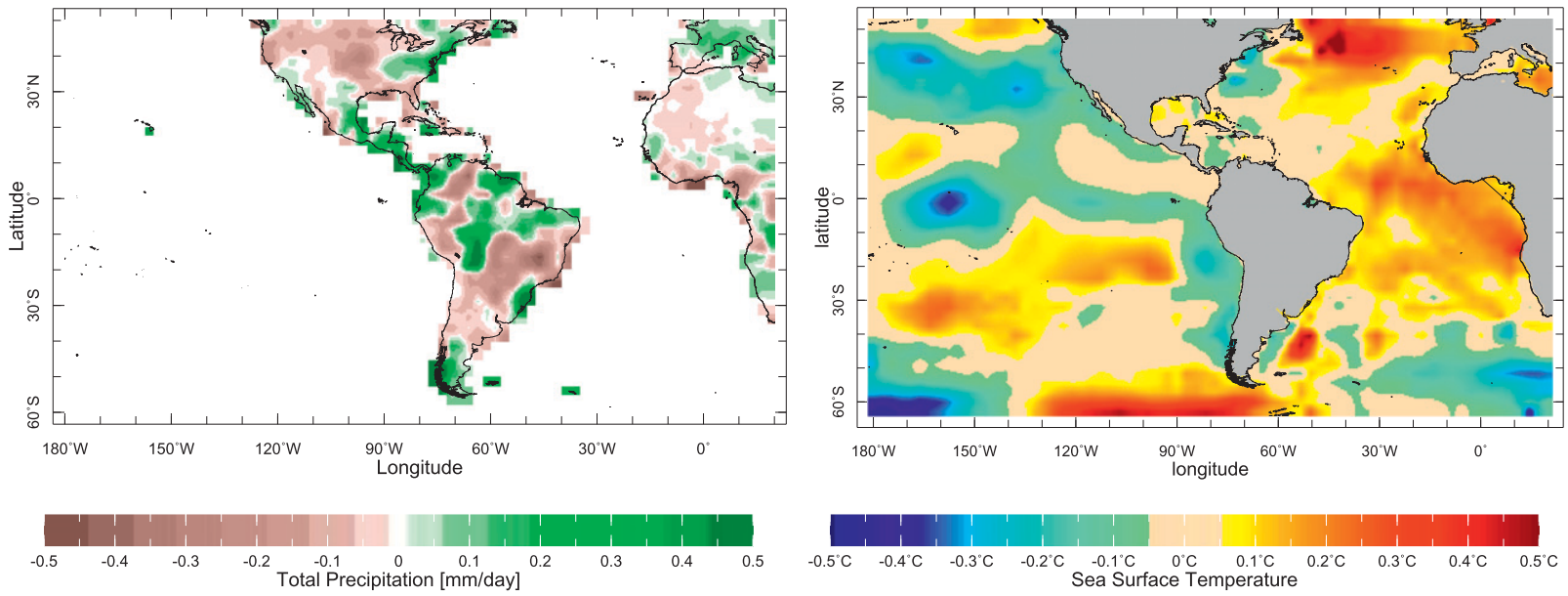

\section{GOGA}

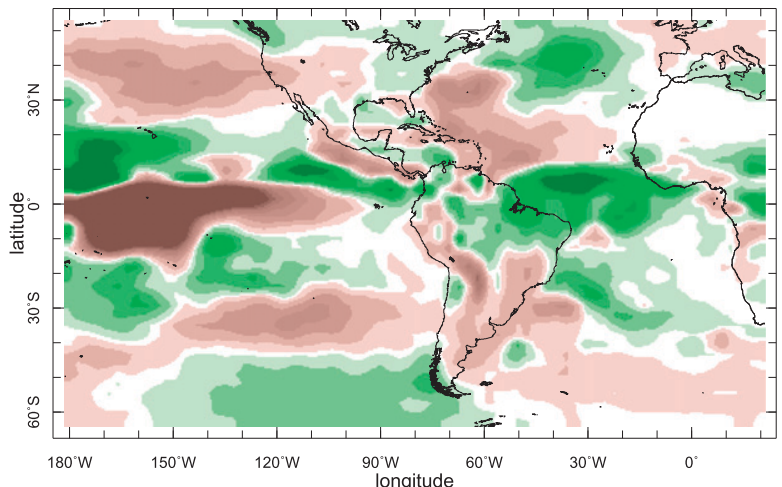

POGA-ML
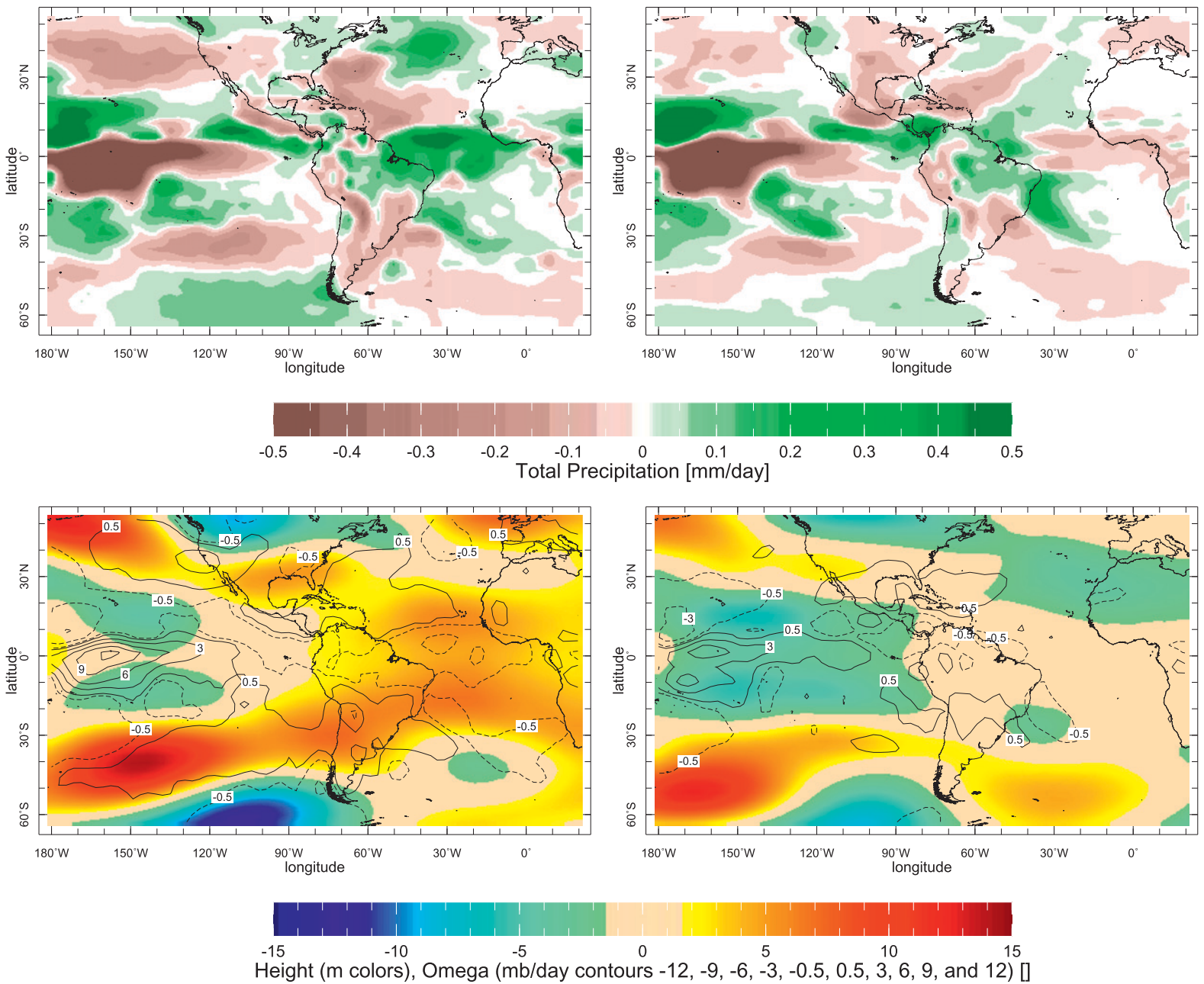

FIG. 16. The (top left) observed precipitation $\left(\mathrm{mm} \mathrm{day}^{-1}\right)$ and (top right) SST (K) anomaly for the 1932-39 period relative to the 19302007 period after detrending. (middle) The modeled precipitation anomalies ( $\mathrm{mm} \mathrm{day}^{-1}$ ) for the (left) GOGA case with global SST forcing and the (right) POGA-ML case with only TP SST forcing. The (bottom left) GOGA- and (bottom right) POGA-ML-modeled 200 -mb heights in colors $(\mathrm{m})$ and vertical pressure velocity $\left(\mathrm{mb} \mathrm{day}^{-1}\right)$ in contours. 
descent over the cold Pacific waters and anomalous ascent over the tropical Atlantic Ocean. The anomalous dry parts of South America have in the GOGA model, as expected, anomalous descending motion above them, consistent with northerly flow generated by the tropical Atlantic heating anomaly. The 200-mb height anomalies in the GOGA model show the effects of both the cold Pacific, where heights are low, and the warm Atlantic, where heights are high, and the wave trains emanating from the Pacific. The eastward-pointing, hemispherically symmetric V shape of heights above the Pacific and Atlantic clearly resembles (with opposite sign) the height anomalies seen in the idealized tropical Atlantic SST anomaly experiments (Fig. 11), suggesting similar dynamics are driving descent over extratropical South America during the 1930s. The POGA-ML model has a purely La Niñadriven signal with much weaker anomalous descent over extratropical South America than the GOGA model, consistent with the weaker precipitation anomaly and the lack of forcing from the tropical Atlantic Ocean. These model comparisons emphasize the role of the Atlantic Ocean in forcing the 1930s Pampas Dust Bowl drought.

It is also the case that warm tropical Atlantic SST anomalies contributed to the North American Dust Bowl drought (Seager et al. 2008); hence, it now appears that these contributed to contemporaneous droughts in the extratropics of both hemispheres. The more severe drought of the two was the North American one, partly because of effective forcing by cold tropical Pacific SST anomalies too. However, soil erosion and dust storms (a result of poor agricultural practices) intensified the drought in the United States (Cook et al. 2009). It is not known if dust storms during the Pampas Dust Bowl also had such an effect but, like its northern cousin, it was initiated by small changes in tropical SSTs.

\section{Implications of climate variations for agriculture in SESA}

SESA is one of the world's main food baskets and food exporters and a key region for global food security. Its relative contribution to global food availability has greatly increased in the last 20 years and is expected to increase further in the coming decades. Large areas of the region have been traditionally used to sustain livestock production based on natural grasslands. But, over the twentieth century, vast regions with fertile soils were gradually converted to croplands even as large areas were kept under grasslands and used for livestock production. However, during the 1990s and 2000s, the rate of agricultural expansion in SESA has drastically increased, driven by increased demand for soybeans and other grains from emerging Asian markets, mainly China and India. This expansion of croplands to regions traditionally considered marginal for crop production, such as the western inland pampas of Argentina (Baldi and Paruelo 2008), was enabled by the increase in precipitation over the last few decades of the twentieth century (Magrin et al. 2005; Giménez and Baethgen 2006). As a consequence of these changes in market conditions and climate, 18 million ha of forests and grasslands in SESA have been converted to croplands since the turn of the century (mainly to soybean but also to maize, wheat, sunflower, and rice).

Even in the absence of climate change, the sustainability of cropland expansion in SESA is being questioned. First, the changes pose a threat to the provision of vital ecosystem services such as carbon sequestration and soil preservation (Viglizzo et al. 1997). Second, grain production is now concentrated in a few large corporations, imposing challenges to the social sustainability of small to medium crop producers and family farmers traditionally devoted to extensive livestock production. Last, some of the lands converted to croplands are considered marginal lands for annual crop production owing to soil physical and chemical properties and/or insufficient rainfall to sustain crop production. On top of these concerns, there is climate change, with the most serious concern being whether the long-term increase in precipitation in SESA that has allowed cropland expansion will continue in the future, as would be expected if it were caused by anthropogenic climate change. The current work suggests that any anthropogenic wetting trend is weak and, instead, the observed trend is strongly influenced by natural multidecadal oscillations of the climate system. If so, then the wetting trend cannot be expected to continue. Consequently, climate variability raises additional concerns for the long-term sustainability of cropland expansion in SESA.

\section{Conclusions}

Precipitation in southeast South America has experienced impressive variations on interannual to multidecadal time scales, including a long-term trend over the latter part of the last century toward a wetter climate. Here we have used observations, climate models forced by historical SSTs and controlled, idealized simulations to address the causes and mechanisms of SESA precipitation variability over the last century. The conclusions are as follows:

1) Amid large-amplitude year-to-year variability, SESA got wetter from the early part of the twentieth century 
to the latter part. The early part of the twentiethcentury instrumental record shows some very large negative precipitation anomalies in individual years and makes it questionable if the wetting trend began before the 1920s.

2) These precipitation variations, on both interannual and multidecadal time scales, are surprisingly well reproduced in atmospheric model simulations forced by historical SSTs from 1901 to 2007. Analysis shows that both tropical Pacific and Atlantic SSTs contribute the main drivers of SESA precipitation variability, with the former dominating on the interannual time scale and the tropical Atlantic dominating on the longer time scales.

3) The strongest correlation of SESA precipitation with SSTs occurs over the tropical Pacific with El Niño conditions leading to increased precipitation, as many others have reported before.

4) The wetting trend from the early to the late twentieth century was largely forced by a relative (to global mean) cooling of the tropical Atlantic Ocean that is related to the cool phase of the Atlantic multidecadal oscillation.

5) The Pampas Dust Bowl drought of the 1930s was forced by tropical SST anomalies, with Atlantic anomalies dominant and was part of a hemispherically symmetric hydroclimate anomaly across the Americas that dynamically linked North and South America.

6) Large ensembles of short atmosphere model simulations in which a tropical Atlantic SSTA was instantaneously imposed on 1 June were analyzed to show the mechanisms whereby this influences SESA precipitation. Cold tropical SSTs induce uppertropospheric convergence and southerly flow over subtropical South America down to about $30^{\circ} \mathrm{S}$. Advection of mean planetary and relative vorticity by this flow is largely balanced by vortex stretching requiring ascent over SESA. This ascent is what causes the increase in precipitation.

7) The wetting trend, and the multidecadal variability in general, is therefore most likely contributed to significantly by natural atmosphere-ocean variability, in which case it cannot be relied upon to last. The 24 models participating in the IPCC AR4 predict a weak increase in SESA precipitation over the last century (and for the next century) as a consequence of anthropogenic climate forcing; thus, anthropogenic forcing may explain some of the observed wet trend in SESA.

In summary, SESA precipitation is strongly controlled by variations of tropical Pacific and Atlantic SSTs, and this should allow useful predictions on the time scales over which these SSTs are themselves predictable. If the Atlantic multidecadal oscillation proves predictable, then it is conceivable that there may be limited predictability of SESA precipitation on the interannual to decadal time scale, information that could be very useful to regional and national governments concerned with water-dependent activities such as agriculture, power generation, and urban water consumption. While the long-term trend toward wetter conditions in SESA was of great benefit to regional agriculture, there is no reason to expect this to continue since it appears to have been strongly influenced by tropical SST anomalies associated with the Atlantic multidecadal oscillation, which is presumed to be of natural origin. For the last 100 years changes in AMO-induced precipitation dwarf those predicted by IPCC AR4 models to have occurred as a consequence of anthropogenic radiative forcing. Indeed, the AMO appears to be shifting toward its positive phase (Ting et al. 2009); if this is so, it may force a decrease in SESA precipitation in the years and decades ahead. Of course, an actual probabilistic prediction would need to take account of the multiple factors influencing SESA precipitation, which not only include tropical SSTs but also the southern annular mode: it would also have to factor in the uncertainties in model projections of anthropogenic hydroclimate change.

Acknowledgments. This work was supported by NOAA Grants NA030AR4320179 PO7 and NA08OAR4320912 and NSF Grants ATM-08-04107 and ATM-05-43256. We thank Lisa Goddard for her comments and advice and the reviewers for their constructive criticisms. SJ was supported by an undergraduate research assistantship from the Earth Institute at Columbia University. The CCM3 model data can be accessed online (at http://kage.ldeo. columbia.edu:81/SOURCES/.LDEO/.ClimateGroup/ .PROJECTS/.CCM3/).

\section{REFERENCES}

Aceituno, P., 1988: On the functioning of the Southern Oscillation in the South American sector. Part I: Surface climate. Mon. Wea. Rev., 116, 505-524.

Andreoli, R. V., and M. T. Kayano, 2005: ENSO-related rainfall anomalies in South America and associated circulation features during warm and cold Pacific Decadal Oscillation regimes. Int. J. Climatol., 25, 2017-2030.

Baldi, G., and J. M. Paruelo, 2008: Land-use and land cover dynamics in South American temperate grasslands. Ecol. Soc., 13, 6. [Available online at http://www.ecologyandsociety.org/ vol13/iss2/art6/.]

Barreiro, M., 2010: Influence of ENSO and the South Atlantic Ocean on climate predictability over southeastern South 
America. Climate Dyn., doi:10.1007/s00382-009-0666-9, in press.

— - P. Chang, and R. Saravanan, 2002: Variability of the South Atlantic convergence zone simulated by an atmospheric general circulation model. J. Climate, 15, 745-763.

Barros, V. R., M. E. Doyle, and I. A. Camilloni, 2008: Precipitation trends in southeastern South America: Relationship with ENSO phases and with low-level circulation. Theor. Appl. Climatol., 93, 19-33.

Boulanger, J., F. Martinez, and E. C. Segura, 2007: Projections of future climate change conditions using IPCC simulations, neural networks and Bayesian statistics. Part 2: Precipitation mean state and seasonal cycle in South America. Climate Dyn., 28, 255-271.

Cazes-Boezio, G., A. W. Robertson, and C. R. Mechoso, 2003: Seasonal dependence of ENSO teleconnections over South America and relationships with precipitation in Uruguay. J. Climate, 16, 1159-1176.

Chan, S. C., S. K. Behera, and T. Yamagata, 2008: Indian Ocean Dipole influence on South American rainfall. Geophys. Res. Lett., 35, L14S12, doi:10.1029/2008GL034204.

Chaves, R. R., and P. Nobre, 2004: Interactions between sea surface temperature over the South Atlantic Ocean and the South Atlantic Convergence Zone. Geophys. Res. Lett., 31, L03204, doi:10.1029/2003GL018647.

Cook, B., R. Miller, and R. Seager, 2009: Amplification of the North American Dust Bowl drought through human-induced land degradation. Proc. Natl. Acad. Sci. USA, 106, 4997-5001.

De Almeida, R. A. F., P. Nobre, R. J. Haarsma, and E. J. D. Campos, 2007: Negative ocean-atmosphere feedback in the South Atlantic Convergence Zone. Geophys. Res. Lett., 34, L18809, doi:10.1029/2007GL030401.

Doyle, M. E., and V. R. Barros, 2002: Midsummer low-level circulation and precipitation in subtropical South America and related sea surface temperature anomalies in the South Atlantic. J. Climate, 15, 3394-3410.

Genta, J. L., G. Perez-Iribarren, and C. R. Mechoso, 1998: A recent increasing trend in the streamflow of rivers in southeastern South America. J. Climate, 11, 2858-2862.

Giannini, A., R. Saravanan, and P. Chang, 2003: Oceanic forcing of Sahel rainfall on interannual to interdecadal timescales. Science, 302, 1027-1030.

Gill, A. E., 1980: Some simple solutions for heat induced tropical circulation. Quart. J. Roy. Meteor. Soc., 106, 447-462.

Giménez, A., and W. E. Baethgen, 2006: SIMERPA: An information and monitoring system for assessing climate risks in agricultural production of Paraguay and Uruguay (in Spanish). Inst. Nac. Invest. Agropecu., 162, 1-45.

Grimm, A. M., 2003: The El Niño impact on the summer monsoon in Brazil: Regional processes versus remote influences. J. Climate, 16, 263-280.

— , and M. T. Zilli, 2009: Interannual variability and seasonal evolution of summer monsoon rainfall in South America. J. Climate, 22, 2257-2275.

_ , V. R. Barros, and M. E. Doyle, 2000: Climate variability in southern South America associated with El Niño and La Niña events. J. Climate, 13, 35-58.

Haarsma, R. J., E. J. D. Campos, and F. Molteni, 2003: Atmospheric response to South Atlantic SST dipole. Geophys. Res. Lett., 30, 1864, doi:10.1029/2003GL017829.

Haylock, M. R., and Coauthors, 2006: Trends in total and extreme South American rainfall in 1960-2000 and links with sea surface temperature. J. Climate, 19, 1490-1512.
Held, I., T. Delworth, J. Lu, K. L. Findell, and T. R. Knutson, 2005: Simulation of Sahel drought in the 20th and 21st centuries. Proc. Natl. Acad. Sci. USA, 102, 17 891-17 896.

Hoerling, M. P., J. W. Hurrell, J. Eischeid, and A. Phillips, 2006: Detection and attribution of twentieth-century northern and southern African rainfall change. J. Climate, 19, 3989-4008.

Huang, H., R. Seager, and Y. Kushnir, 2005: The 1976/77 transition in precipitation over the Americas and the influence of tropical SST. Climate Dyn., 24, 721-740.

Kalnay, E., and Coauthors, 1996: The NCEP/NCAR 40-Year Reanalysis Project. Bull. Amer. Meteor. Soc., 77, 437-471.

Kaplan, A., M. A. Cane, Y. Kushnir, A. C. Clement, M. B. Blumenthal, and B. Rajagopalan, 1998: Analyses of global sea surface temperature, 1856-1991. J. Geophys. Res., 103, 18 567-18 589.

Karoly, D. J., 1989: Southern Hemisphere circulation features associated with El Niño-Southern Oscillation events. J. Climate, 2, 1239-1252.

Kidson, J. W., 1999: Principal modes of Southern Hemisphere lowfrequency variability obtained from NCEP-NCAR reanalyses. J. Climate, 12, 2808-2830.

Kiehl, J. T., J. J. Hack, G. B. Bonan, B. A. Boville, D. L. Williamson, and P. J. Rasch, 1998: The National Center for Atmospheric Research Community Climate Model: CCM3. J. Climate, 11, 1131-1149.

Kistler, R., and Coauthors, 2001: The NCEP-NCAR 50-Year Reanalysis: Monthly means CD-ROM and documentation. Bull. Amer. Meteor. Soc., 82, 247-268.

L'Heureux, M. L., and D. W. J. Thompson, 2006: Observed relationships between the El Niño-Southern Oscillation and the extratropical zonal mean circulation. J. Climate, 19, 276-287.

Liebmann, B., and Coauthors, 2004: An observed trend in central South American precipitation. J. Climate, 17, 4357-4367.

Magrin, G. O., M. I. Travasso, and G. R. Rodriguez, 2005: Changes in climate and crop production during the 20th century in Argentina. Climatic Change, 72, 229-249.

Meehl, G., C. Covey, T. Delworth, M. Latif, B. McAvaney, J. F. B. Mitchell, R. J. Stouffer, and K. E. Taylor, 2007: The WCRP CMIP3 multimodel dataset: A new era in climate change research. Bull. Amer. Meteor. Soc., 88, 1383-1394.

Mo, K. C., and R. W. Higgins, 1998: The Pacific-South American modes and tropical convection during the Southern Hemisphere winter. Mon. Wea. Rev., 126, 1581-1596.

_ , and J. N. Paegle, 2001: The Pacific-South American modes and their downstream effects. Int. J. Climatol., 21, 1211-1229.

Paegle, J. N., and K. C. Mo, 2002: Linkages between summer rainfall variability over South America and sea surface temperature anomalies. J. Climate, 15, 1389-1407.

Pezzi, L. P., and I. F. A. Cavalcanti, 2001: The relative importance of ENSO and tropical Atlantic sea surface temperature anomalies for seasonal precipitation over South America: A numerical study. Climate Dyn., 17, 205-212.

Pisciottano, G., A. Díaz, G. Cazes, and C. R. Mechoso, 1994: El Niño-Southern Oscillation impact on rainfall in Uruguay. J. Climate, 7, 1286-1302.

Rayner, N., D. Parker, E. Horton, C. Folland, L. Alexander, D. Rowell, E. Kent, and A. Kaplan, 2003: Global analyses of sea surface temperature, sea ice, and night marine air temperature since the late nineteenth century. J. Geophys. Res., 108, 4407, doi:10.1029/2002JD002670.

Robertson, A. W., and C. R. Mechoso, 1998: Interannual and decadal cycles in river flows of southeastern South America. $J$. Climate, 11, 2570-2581. 
— and - 2000: Interannual and interdecadal variability of the South Atlantic convergence zone. Mon. Wea. Rev., 128, 2947-2957.

Rudolf, B., H. Hauschild, W. Rueth, and U. Schneider, 1994: Terrestrial precipitation analysis: Operational analysis and required density of point measurements. Global Precipitation and Climate Change, M. Desbois and F. Desalmond, Eds., Springer Verlag, 173-186.

Schneider, U., T. Fuchs, A. Meyer-Christoffer, and B. Rudolf, 2008: Global precipitation analysis products of the GPCC. Global Precipitation Climatology Centre Tech. Rep., 12 pp.

Schubert, S. D., M. J. Suarez, P. J. Pegion, R. D. Koster, and J. T. Bacmeister, 2004a: Causes of long-term drought in the U.S. Great Plains. J. Climate, 17, 485-503.

,,,$--- \ldots$, and,$- 2004 \mathrm{~b}$ : On the cause of the 1930s Dust Bowl. Science, 303, 1855-1859.

Seager, R., N. Harnik, Y. Kushnir, W. Robinson, and J. Miller, 2003: Mechanisms of hemispherically symmetric climate variability. J. Climate, 16, 2960-2978.

, W. A. Robinson, Y. Kushnir, M. Ting, H. P. Huang, and J. Velez, 2005a: Mechanisms of ENSO-forcing of hemispherically symmetric precipitation variability. Quart. J. Roy. Meteor. Soc., 131, 1501-1527.

_ , Y. Kushnir, C. Herweijer, N. Naik, and J. Velez, 2005b: Modeling of tropical forcing of persistent droughts and pluvials over western North America: 1856-2000. J. Climate, 18, 4068-4091.

M. Ting, M. A. Cane, N. Naik, and J. Velez, 2008: Would advance knowledge of 1930s SSTs have allowed prediction of the Dust Bowl drought? J. Climate, 21, 3261-3281. , A. Tzanova, and J. Nakamura, 2009a: Drought in the southeastern United States: Causes, variability over the last millennium, and the potential for future hydroclimate change. J. Climate, 22, 5021-5045.
- , and Coauthors, 2009b: Mexican drought: An observational, modeling and tree ring study of variability and climate change. Atmósfera, 22, 1-31.

Silvestri, G., and C. Vera, 2003: Antarctic Oscillation signal on precipitation anomalies over southeastern South America. Geophys. Res. Lett., 30, 2115, doi:10.1029/2003GL018277.

$\longrightarrow$, and —, 2009: Nonstationary impacts of the southern annular mode on Southern Hemisphere climate. J. Climate, 22, 6142-6148.

Taschetto, A. S., and I. Wainer, 2008: The impact of the subtropical South Atlantic SST on South American precipitation. Ann. Geophys., 26, 3457-3476.

Thompson, D. W. J., and J. M. Wallace, 2000: Annular modes in the extratropical circulation. Part I: Month-to-month variability. J. Climate, 13, 1000-1016.

Ting, M., Y. Kushnir, R. Seager, and C. Li, 2009: Forced and internal twentieth-century SST trends in the North Atlantic. J. Climate, 22, 1469-1481.

Trzaska, S., A. W. Robertson, J. D. Farrara, and C. R. Mechoso, 2007: South Atlantic variability arising from air-sea coupling: Local mechanisms and tropical-subtropical interactions. J. Climate, 20, 3345-3365.

Vera, C., G. Silvestri, B. Liebmann, and P. González, 2006: Climate change scenarios for seasonal precipitation in South America from the IPCC-AR4 models. Geophys. Res. Lett., 33, L13707, doi:10.1029/2006GL025759.

Viglizzo, E., and F. C. Frank, 2006: Ecological interactions, feedbacks, thresholds and collapses in the Argentine Pampas in response to climate and farming during the last century. Quat. Int., 158, 122-126.

— Z. Z. E. Roberto, F. Lértora, E. López Gay, and J. Bernardos, 1997: Climate and land-use change in field-crop ecosystems of Argentina. Agric. Ecosyst. Environ., 66, 61-70. 